\title{
Mechanisms of Coordination in Distributed Neural Circuits: Encoding Coordinating Information
}

\author{
Carmen Smarandache-Wellmann and Swantje Grätsch \\ Emmy Noether Group/Institute of Zoology, University of Cologne, D50674 Cologne, Germany
}

We describe synaptic connections through which information essential for encoding efference copies reaches two coordinating neurons in each of the microcircuits that controls limbs on abdominal segments of the crayfish, Pacifastacus leniusculus. In each microcircuit, these coordinating neurons fire bursts of spikes simultaneously with motor neurons. These bursts encode timing, duration, and strength of each motor burst. Using paired microelectrode recordings, we demonstrate that one class of nonspiking neurons in each microcircuit's pattern-generating kernel-IPS - directly inhibits the $\mathrm{ASC}_{\mathrm{E}}$ coordinating neuron that copies each burst in power-stroke (PS) motor neurons. This inhibitory synapse parallels IPS's inhibition of the same PS motor neurons. Using a disynaptic pathway to control its membrane potential, we demonstrate that a second type of nonspiking interneuron in the pattern-generating kernel-IRSh-inhibits the DSC coordinating neuron that copies each burst in return-stroke (RS) motor neurons. This inhibitory synapse parallels IRS's inhibition of the microcircuit's RS motor neurons. Experimental changes in the membrane potential of one IPS or one IRSh neuron simultaneously changed the strengths of motor bursts, durations, numbers of spikes, and spike frequency in the simultaneous ASC ${ }_{\mathrm{E}}$ and DSC bursts.

$\mathrm{ASC}_{\mathrm{E}}$ and DSC coordinating neurons link the segmentally distributed microcircuits into a coordinated system that oscillates with the same period and with stable phase differences. The inhibitory synapses from different pattern-generating neurons that parallel their inhibition of different sets of motor neurons enable $\mathrm{ASC}_{\mathrm{E}}$ and DSC to encode details of each oscillation that are necessary for stable, adaptive synchronization of the system.

Key words: central pattern generators; efference copy; locomotion; swimmeret rhythm; synaptic range

\section{Introduction}

In segmented animals, the CNS is composed of segmental microcircuits whose activity is coordinated to produce effective periodic behaviors. These microcircuits are linked together by coordinating circuits that synchronize their activity and establish their essential phase relationships. Crucial components of many coordinating circuits are "efference copy" (EC) neurons that encode information about a microcircuit's activity and conduct it to other parts of the CNS.

The swimmeret system of crayfish drives periodic powerstroke (PS) and return-stroke (RS) movement in four pairs of abdominal limbs. Each limb is innervated by a microcircuit lo-

\footnotetext{
Received June 23, 2013; revised March 3, 2014; accepted March 7, 2014.

Author contributions: C.S.-W. designed research; C.S.-W. and S.G. performed research; C.S.-W. and S.G. analyzed data; C.S.-W. wrote the paper.

This research was supported by an Emmy Noether Deutsche Forschungsgemeinschaft grant SM 206/3-1 and a startup grant from the University of Cologne for female faculty. Cynthia Weller, who was supported by National Science Foundation grants 09-05063 and 11-47058 to Brian Mulloney (University of California, Davis), contributed the anatomical illustrations in Figures 2,8, and 9 . We especially thank Brian Mulloney for his constructive comments on this manuscript and the broad discussions and guidance. We thank Ansgar Büschges for many conversations about coordination of microcircuits. We are grateful to Ingo Selbach for his efforts to supply the lab with experimental animals.

The authors declare no competing financial interests.

Correspondence should be addressed to Carmen Smarandache-Wellmann, University of Cologne, Emmy Noether Group/Institute of Zoology, Zuelpicher Strasse 47b, D-50674 Cologne, Germany. E-mail: carmen.wellmann@uni-koeln.de.

DOI:10.1523/JNEUROSCI.2670-13.2014

Copyright $\odot 2014$ the authors $\quad 0270-6474 / 14 / 345627-13 \$ 15.00 / 0$
}

cated in each abdominal hemiganglion (Fig. 1A,B). These microcircuits are able to produce PS-RS alternation on their own because of the pattern-generating kernel formed by reciprocal inhibition between two sets of nonspiking interneurons, IPS and IRS (Smarandache-Wellmann et al., 2013). IPS neurons directly inhibit the microcircuit's PS motor neurons, while IRS neurons directly inhibit RS motor neurons (Fig. 1C; Mulloney, 2003).

Whenever the system is active, coordinating neurons link the chain of distributed microcircuits together and synchronize their activity. From each circuit, one $\mathrm{ASC}_{\mathrm{E}}$ coordinating neuron projects anteriorly, and one DSC coordinating neuron projects posteriorly (Fig. 1B; Smarandache et al., 2009). The $\mathrm{ASC}_{\mathrm{E}}$ neuron fires in phase with PS activity in its own microcircuit, while the DSC neuron fires in phase with RS activity (Fig. 1D). Axons of these two neurons conduct information about timing, duration, and strength of each burst of spikes in their own microcircuit's motor neurons to all anterior and posterior microcircuits in the swimmeret system (Fig. 1B; Namba and Mulloney, 1999; Mulloney et al., 2006). This information is essential for synchronizing swimmeret movement in different segments of the body. Changes in the timing or strength of these bursts affect the timing and strength of motor output from the other microcircuits to which axons of these coordinating neurons project (Mulloney and Hall, 2007).

These new insights into the organization of these microcircuits and their coordinating circuit (Fig. 1) permitted this analy- 
sis of how coordinating information is encoded in the identified EC neurons, $\mathrm{ASC}_{\mathrm{E}}$ and DSC. We used paired microelectrode recordings to investigate synaptic connections between coordinating neurons and nonspiking local patterngenerating interneurons in the same microcircuit. We found a strong and direct graded inhibitory synapse from IPS onto $\mathrm{ASC}_{\mathrm{E}}$ neurons, and strong evidence that IRSh shapes DSC activity. We measured the working ranges of the graded synapses between these interneurons and coordinating neurons. These nonspiking interneurons change the activity of coordinating neurons monotonically within a presynaptic range of $\sim 25 \mathrm{mV}$. This externally regulated $\mathrm{ASC}_{\mathrm{E}}$ and DSC firing had a significant effect on the motor output in the neighboring microcircuits.

These synapses from pattern-generating neurons onto DSC and $\mathrm{ASC}_{\mathrm{E}}$ parallel the graded inhibitory synapses that shape the firing of different sets of motor neurons, and provide an explanation of how and why these coordinating neurons encode detailed efference copies of each cycle of their microcircuit's motor output.

\section{Materials and Methods}

Crayfish, Pacifastacus leniusculus, of both sexes were caught in a nearby river by a local fisherman and held in aerated fresh water tanks at $14^{\circ} \mathrm{C}$. Before dissection, the animals were anesthetized by chilling on ice and exsanguinated by transfusion with cold saline. For these experiments, the six abdominal ganglia (A1 to A6; Fig. $1 A$ ) and the last two thoracic ganglia (T5 and T4) were isolated. The nerve cord was placed in a Petri dish lined with transparent Sylgard (Dow-Corning). The chain of eight ganglia was pinned out linearly, dorsal side up. The dorsal sides of all ganglia (T4 to A6) were desheathed with sharp microscissors so drugs could reach the lateral neuropil (LN; Mulloney et al., 2003) of each ganglion more rapidly and so that sharp microelectrodes could easily penetrate the dendritic arbors of neurons in the LN (Figs. 2B, $8 B, 9 B$ ).

Electrophysiological solutions. Normal saline was prepared as described previously (Smarandache et al., 2009) and contained the following (in mм): $5.4 \mathrm{KCl}, 2.6 \mathrm{MgCl}_{2}, 13.5 \mathrm{CaCl}_{2}, 195 \mathrm{NaCl}$, buffered with $10 \mathrm{~mm}$ Tris base, and $4.7 \mathrm{~mm}$ maleic acid at $\mathrm{pH}$ 7.4. In some preparations the nervous system did not express spontaneous activity in normal saline, so to activate the system we used low concentrations ( 1 to maximum $3 \mu \mathrm{M}$ ) of carbachol (Sigma) dissolved in normal saline (Mulloney, 1997).

Electrophysiological recordings. In abdominal ganglia A2 through A5 (Fig. 1A), the paired segmental nerves, N1, contain only axons of motor and sensory neurons that innervate the four pair of swimmerets. From each hemiganglion, motor neurons that innervate the PS muscles project through the posterior branch of $\mathrm{N} 1$, and motor neurons that innervate RS muscles project through the anterior N1 branch (Fig. $1 A$; Mulloney and Smarandache-Wellmann, 2012). In each experiment, we recorded the firing of the PS motor neurons from all ganglia A2 to A5 using extracellular stainless steel pin electrodes placed on the posterior N1 branch (Fig. 1A) and insulated from the bathing solution with petroleum jelly. The reference electrode was placed in the bath nearby.

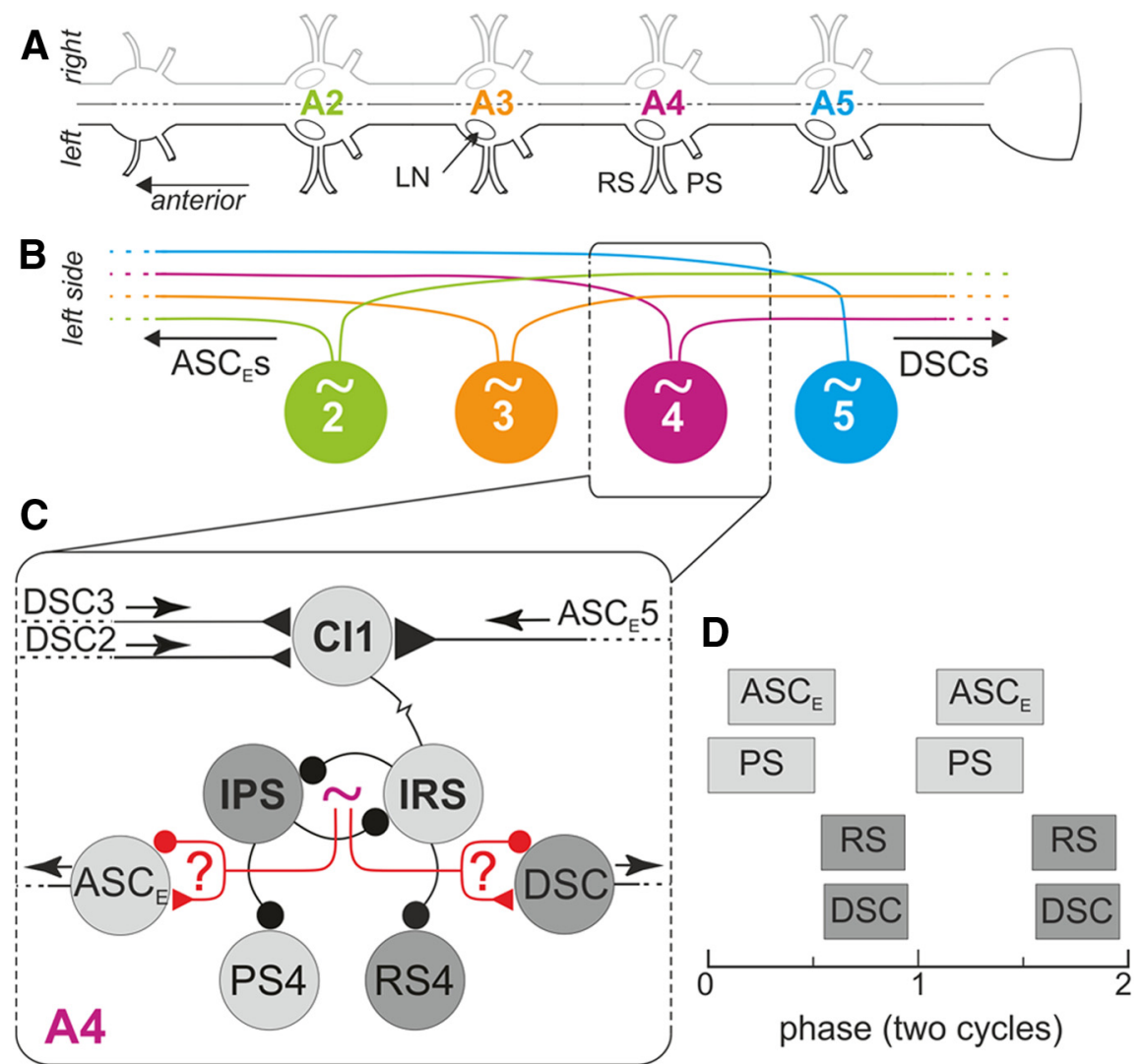

Figure 1. Segmental organization of the swimmeret system of crayfish. $A$, The abdominal nerve cord and its ganglia $A 1$ to $A 6$ is part of the CNS. Only ganglia A2 to A5 innervate the four pairs of swimmerets in the crayfish, $P$. leniusculus. The system is bilaterally symmetric, and for these experiments, only information from the ipsilateral side was relevant. $\boldsymbol{B}$, Each swimmeret is driven by its own local microcircuit $(\sim)$, represented by the large colored circle. The color scheme will be preserved throughout this paper to 列 microcircuit and potential connections from the pattern-generating kernel of the microcircuit to the coordinating neurons $A S C_{E}$ and DSC. The intent of this investigation is to determine which of the two interneurons (IPS or IRS) directly tunes the activity of ASC $_{E}$ and DSC. All neurons active in phase are depicted by the same gray gradient. Filled black circle: inhibitory synapse; triangle: itatory synapse. Size represents gradient of synaptic strength. Red connections are the possible connections from the patternutput from one module. A PS burst starts each cycle. RS bursts occur in antiphase. The timing of the coordinating neurons is correlated with this activity; $\mathrm{ASC}_{\mathrm{E}}$ is active in phase with PS while DSC is in phase with RS motor neurons.

All extracellular recordings were amplified, filtered using Model 102 extracellular amplifiers (Electronics Lab, University of Cologne, Germany), and digitized using Digidata 1440A and pClamp software (Molecular Devices). The data files were recorded and saved on a computer for later analysis.

Intracellular recordings of swimmeret neurons. Sharp microelectrodes were pulled with a P-1000 micropipette puller (Sutter Instruments) and filled with a solution of $1 \mathrm{M} \mathrm{K}^{+}$acetate $+0.1 \mathrm{M} \mathrm{KCl}$ and either $1 \%$ dextran Texas Red (dTR; MW 3000, lysine fixable; Invitrogen) or 5\% Neurobiotin (NB; Biozol; Vector Laboratories). The tip resistance of these electrodes was between 30 and $50 \mathrm{M} \Omega$. The sharp tips enabled good, stable intracellular recordings from fine dendritic branches of the neurons in the LN.

At the end of each experiment, neurons were filled with dye for $20 \mathrm{~min}$ using a train of $+1 \mathrm{nA}$ current pulses, $250 \mathrm{~ms}$ long, at $2 \mathrm{~Hz}$ to confirm the physiological identification (see below). Ganglia were then fixed in $4 \%$ paraformaldehyde in PBS for at least $2 \mathrm{~h}$ at room temperature, or in the fridge overnight. After fixation, ganglia with dye-filled neurons were washed three times for $10 \mathrm{~min}$ in phosphate buffer containing $0.1 \mathrm{M}$ glycine. Ganglia were then dehydrated in an ascending ethanol series $(25$, $50,70,80,95$, and 100\%). Ganglia containing an NB-filled neuron were processed following the protocol from Smarandache-Wellmann et al. 

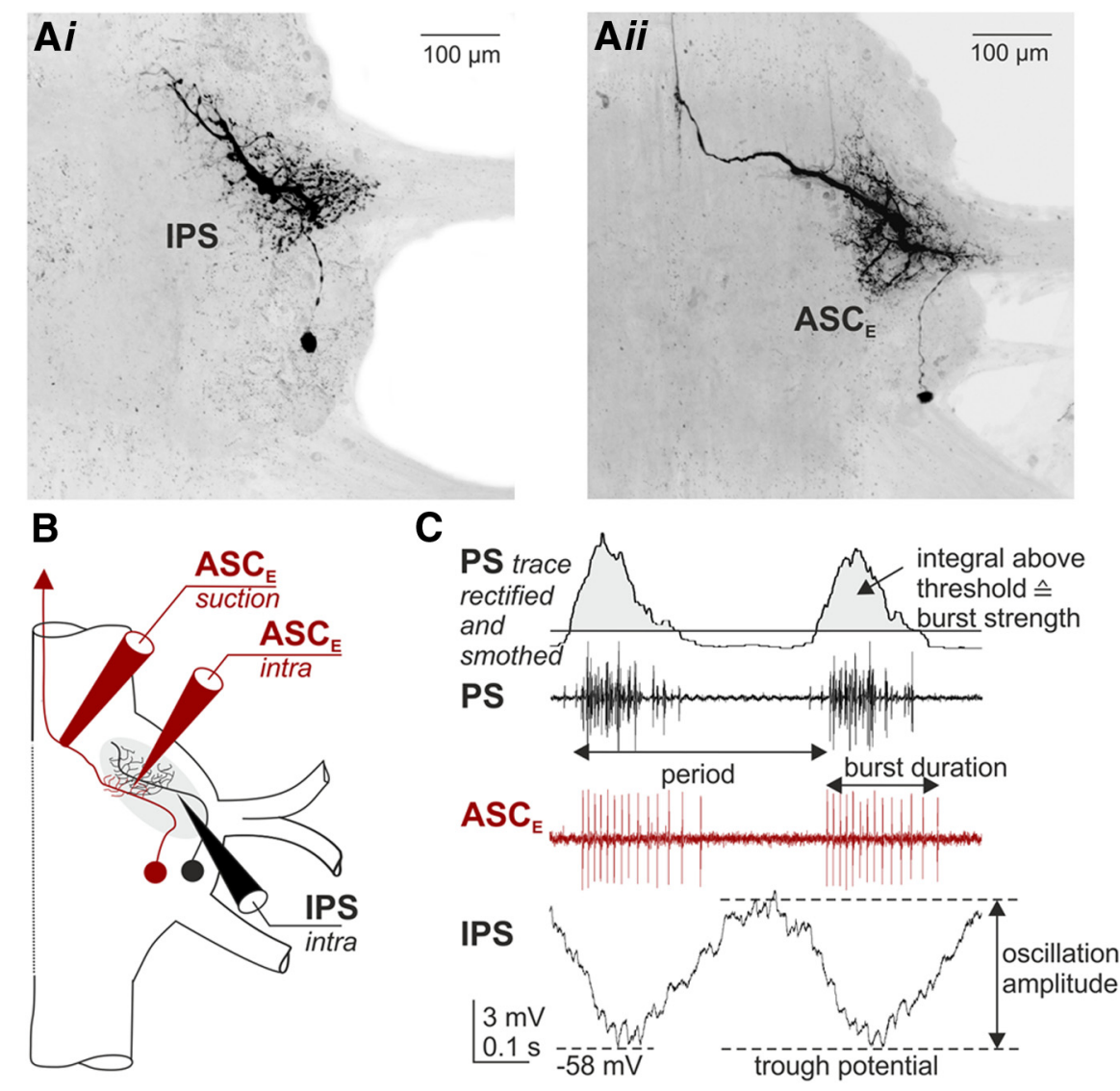

Figure 2. A, Two whole-mount preparations of two different abdominal ganglia, seen from the dorsal side. Ai, IPS filled with dTR. Aii, One ASC $C_{E}$ neuron filled with dTR. The soma of $A S_{E}$ is posterior to the base of $\mathrm{N} 1$, and is located in the same region as the IPS soma. $B$, Schematic drawing of the placement of the sharp intracellular electrodes for IPS and $\mathrm{ASC}_{\mathrm{E}}$. Alternatively, $\mathrm{ASC}_{\mathrm{E}}$ was recorded extracellularly with a suction electrode placed on the anterior $\mathrm{MnT}$ where $\mathrm{ASC}_{\mathrm{E}}{ }^{\prime} S$ axon passes dorsally to the $\mathrm{LG}$. $C$, Simultaneous extracellular recordings of $\mathrm{PS}$ and $\mathrm{ASC}_{\mathrm{E}}$ and intracellular recording of IPS, all from the same microcircuit, depicting the parameters (period, burst duration, and burst strength) measured in each experiment. PS burst strength was measured by rectifying and smoothing the extracellular recording, with the integral above a threshold representing the burst strength. IPS potential oscillated with the motor output, always hyperpolarizing during $\mathrm{PS}$ and $\mathrm{ASC}_{\mathrm{E}}$ bursts and depolarizing during the interburst interval. The "trough potential" was the most hyperpolarized potential during the oscillation, and the oscillation amplitude was measured from the trough potential to the peak of the oscillation.

(2013). Preparations containing only dTR were mounted in methyl salicylate. Confocal images were made with a Zeiss LSM 510 Meta confocal microscope.

Intracellular signals were amplified using the npi SEC $05 \times$ amplifier (npi Electronic Instruments). Measurements and current injections were performed using either discontinuous single-electrode voltage-clamp mode $(\mathrm{dSeVC})$ or discontinuous current-clamp mode (DCC). During $\mathrm{dSeVC}$ or DCC recordings the clocks of the two npi SEC $05 \times$ were synchronized and a grounded aluminum blade was placed between the two head stages to reduce cross talk. To minimize electrode capacitance during these experiments, the level of saline in the dish was kept low and the tips of the microelectrodes were coated with Sylgard 189 to minimize capacitance of the tip. We usually attained switching frequencies between 25 and $35 \mathrm{kHz}$

Physiological identification of neurons. Each swimmeret microcircuit is located on one side of one of four abdominal ganglia (Fig. 1B). Each microcircuit produces alternating bursts of spikes in PS and RS branches of N1 (Fig. $1 A, D$ ) that drive the swimmeret's periodic movements. Most dendritic branches of a microcircuit's motor neurons, patterngenerating interneurons, and coordinating neurons are restricted to one LN (Fig. 1A), where all synaptic contacts within the microcircuit are located. Intracellular recordings were made from processes of individual neurons in the LN using sharp microelectrodes. Each neuron was first tentatively identified using physiological criteria, and its identity was confirmed following an examination of its anatomy.
$\mathrm{ASC}_{\mathrm{E}}$ (ascending coordinating neuron) and DSC (descending coordinating neuron) coordinating neurons occur as single copies in each microcircuit and can be identified by specific physiological and anatomical criteria (Namba and Mulloney, 1999). The soma of ASC $_{\mathrm{E}}$ lies posterior to the base of $\mathrm{N} 1$, and its dendrites arborize in the LN. Its axon projects dorsally from the LN through the anterior minuscule tract $(\mathrm{MnT})$ toward the midline, crosses dorsal to the lateral giant axon (LG), and then turns anteriorly to enter the interganglionic connectives. Spikes in each $\mathrm{ASC}_{\mathrm{E}}$ can be recorded with a suction electrode placed where it crosses the LG. The soma of DSC is located anterior to the base of $\mathrm{N} 1$, and its dendrites also arborize in the LN. Its axon projects dorsally through the posterior MnT toward the midline, and crosses dorsal to the LG axon before turning posteriorly to enter the intersegmental connective. Spikes in each DSC axon can be recorded with a suction electrode as it crosses the LG axon.

The IPS (Inhibitor of Power-Stroke) and IRS (Inhibitor of Return-Stroke) neurons that form the pattern-generating kernel within each microcircuit are nonspiking local neurons whose anatomy is also restricted to one side of the ganglion (Smarandache-Wellmann et al., 2013). They have distinctive physiological properties, and their identification can be confirmed by anatomical criteria. Each IPS soma is located posterior to the base of N1, in the same region as ASC $_{\mathrm{E}}$ 's soma, and each IPS neuron's dendritic arbor is restricted to the LN (Smarandache-Wellmann et al., 2013).

Commissural interneuron 1s (ComInt1s) are nonspiking bilateral local neurons. The soma of each ComInt1 is located posterior to N1. From here, its primary neurite projects medially across the midline through Dorsal Commissure 3 (Mulloney et al., 2003), where it extends a few small dendrites. The primary neurite then continues away from the midline into the LN contralateral to its soma, where its terminal dendrites arborize (Mulloney and Hall, 2003; Smarandache et al., 2009). ComInt1 was recorded intracellularly either at the midline or in the LN (Smarandache et al., 2009).

Testing for direct synaptic connections between neurons. To discover connections between two neurons in the same microcircuit, a series of $>20$ small current pulses $50 \mathrm{~ms}$ long was applied to one neuron and the response in the putative postsynaptic cell was recorded. Overlays of at least 20 sweeps triggered on the current pulse were used to analyze any postsynaptic responses. Averages of these sweeps were computed in Clampfit or Spike2 Version 7 (Cambridge Electronics Design), and the delay from the start of the current pulse to any postsynaptic response was measured. If a response was observed in the first $3.5 \mathrm{~ms}$ following each stimulus, the two cells were considered to be directly connected via chemical synapses (Smarandache-Wellmann et al., 2014).

Data analysis. To describe changes in the output of the swimmeret system, we measured the period of the motor pattern, the durations of bursts, the frequencies of spikes within bursts, and the phases of bursts within each cycle. The period was measured as the time from the first spike of each PS burst to the first spike of the next PS burst (Fig. 2C). In some analyses, the period was instead measured from the start of one ASC $_{\mathrm{E}}$ burst to the start of the next $\mathrm{ASC}_{\mathrm{E}}$ burst, or from the start of one DSC burst to the start of the next DSC burst. These cases are identified (see Results). Burst duration was measured as the time from the first to the last spike of a burst (Fig. 2C, 9B). Frequency of spikes in a burst was calculated by counting the number of spikes in one burst minus 1 , di- 
vided by the burst's duration. Phase within a cycle of output was calculated as the ratio of the latency, the time from the beginning of the period to the beginning of the event, to the period of the cycle.

Measuring input resistance $\left(R_{\text {in }}\right)$ of $A S C_{E}$. For these experiments, $\mathrm{ASC}_{\mathrm{E}}$ was recorded intracellularly in DCC mode. Short $-1 \mathrm{nA}$ current pulses, $50 \mathrm{~ms}$ duration, were applied every $4 \mathrm{~s}$ at different phases of the rhythm. $R_{i n}$ was calculated using Ohm's Law as the change in membrane potential divided by the applied current, and normalized to the highest input resistance recorded in each experiment. At least 100 measurements evenly distributed over the whole cycle were plotted as a function of the phase of the stimulus. To assess the statistical properties of these measurements, individual measurements were binned in 0.05-phase steps and the mean \pm SD was calculated for each bin.

Measuring strengths of PS and $A S C_{E}$ bursts. To measure changes in strengths of extracellularly recorded PS bursts, we used two procedures to calculate the area under the curve of smoothed, rectified bursts. In the first, we imported the recording into Sigma Plot (Version 12; Systat Software) using DataAccess (Bruxton) and applied the algorithm described previously (Mulloney, 2005). The trace was rectified by squaring each measurement point, and smoothed using a fast Fourier transform (FFT) with a triangular kernel. The smoothed recording was restored using an inverse FFT, and plotted as a function of time. By defining a threshold above the noise in this smoothed recording, each burst was isolated and its area was calculated using a SigmaPlot function.

Burst strengths were also measured with Spike2. In this software, the channel offset for each recording was set to zero by using the channel process function "DC remove". Then each recording was rectified and smoothed with a rate of $\sim 0.03$. The start and end of each burst was marked on separate event traces. Using a Spike2 script (courtesy of Dr. A. Borgmann), the area of each burst was calculated as the integral from its start to its end. The two procedures yielded the same results. To permit comparisons of different recordings and experiments, the strength of each burst was normalized to the strongest burst in the recording.

Since each spike in an $\mathrm{ASC}_{\mathrm{E}}$ burst can be counted, the strengths of these bursts were calculated simply as the product of the duration and the number of spikes in each burst. For each experiment, these strengths were normalized to the strongest burst.

Measuring responses to changes in presynaptic membrane potential. Spikes in axons of coordinating neurons were recorded extracellularly with suction electrodes while the membrane potential of an identified presynaptic interneuron was controlled using either $\mathrm{dSeVC}$ or DCC mode to measure the working range of the synapse. Each interneuron was first held for at least $30 \mathrm{~s}$ at its "trough potential", the most hyperpolarized potential it reached during free-running oscillations (Fig. 2C), and then depolarized in steps $(1 \mathrm{mV}$ for IPS experiments, $3 \mathrm{mV}$ for ComInt 1 experiments) up to $-10 \mathrm{mV}$. At each step, the neuron was held for at least 30 cycles of motor output. From this maximum depolarization, the neuron was repolarized in steps of the same size down to $-100 \mathrm{mV}$.

Firing of the coordinating neuron that had been recorded at each step was analyzed using another Spike2 script. After marking each spike of a coordinating neuron on an event channel, the script calculated the numbers of spikes per burst, burst durations, spike frequency within each burst, and cycle period. These calculations were performed on at least 15 consecutive bursts recorded at each holding potential. Coordinating neurons in more anterior ganglia (Fig. 1) fire on average fewer spikes per burst in each cycle than do those in posterior ganglia (Mulloney et al., 2006). Therefore, to facilitate comparison of results from different ganglia and different experiments, we calculated parameters from each recording were normalized to the highest recorded value. The means $\pm \mathrm{SD}$ of each parameter at each holding potential were plotted versus presynaptic membrane potential, and the results were tested for normal distribution in SigmaPlot. These data were also fitted with robust Lowess curves in MATLAB (MathWorks; Cleveland, 1979) and the resulting curves were plotted using SigmaPlot.

These methods allow accurate measurement of the membrane potential at the recording site, but because IPS neurons and particularly ComInt 1 are probably not electrically compact the potentials at more distant synaptic contacts cannot be accurately recorded. However,
dSeVC of ComInt 1 effectively halts synaptically driven oscillations of its membrane potential, allows quantitative control of the microcircuit's operations by quantitative changes in ComIntl's potential (Smarandache-Wellmann et al., 2014), and is an effective and appropriate tool here for probing synaptic transmission.

Figures. All diagrams were prepared using Sigma Plot (Version 12). Figures were prepared in Corel Draw X6. Confocal images of the interneurons were created from $z$-stacks and the brightness and hue were adjusted in Photoshop using protocols described previously (SmarandacheWellmann et al., 2013).

\section{Results}

\section{Encoding of coordinating information}

To discover how coordinating information is encoded in this system, we investigated how neurons in the pattern-generating kernel connect with coordinating neurons (Fig. 1C). In each microcircuit, two coordinating neurons, $\mathrm{ASC}_{\mathrm{E}}$ and DSC, encode efference copies of their own microcircuit's motor output and conduct them to all anterior and posterior segments (Fig. $1 A, B$ ). Since $\mathrm{ASC}_{\mathrm{E}}$ is always active in time with PS motor neurons, there are only two simple ways that the kernel might drive this activity: either by an inhibitory connection from IPS onto ASC $_{\mathrm{E}}$ or by an excitatory connection from IRS onto $\mathrm{ASC}_{\mathrm{E}}$. Similarly, DSC might be driven by an inhibitory connection from IRS or an excitatory connection from IPS. To test these alternative hypotheses, we made simultaneous intracellular and extracellular recordings from pattern-generating interneurons and $\mathrm{ASC}_{\mathrm{E}}$ or DSC neurons in the same microcircuit.

\section{IPS, a nonspiking interneuron, shapes $\mathrm{ASC}_{\mathrm{E}}$ output by direct inhibition}

We began by recording intracellularly from an IPS (Fig. $2 A i, B$ ) and an $\mathrm{ASC}_{\mathrm{E}}$ neuron (Fig. $2 A i i, B$ ) in the same microcircuit (Fig. $3 A, B)$. Depolarization of the $\mathrm{ASC}_{\mathrm{E}}$ neuron had no apparent effect on IPS's membrane potential, and only PS activity in the next anterior segment was affected (Fig. 3Ai; Namba and Mulloney, 1999). Changes in an IPS's membrane potential affected mainly its own microcircuit (Fig. 3Aii). When IPS was depolarized to $-20 \mathrm{mV}$, PS activity in the same segment stopped, as expected. $\mathrm{ASC}_{\mathrm{E}}$ 's firing also stopped, and its membrane potential hyperpolarized. When IPS was hyperpolarized to $-90 \mathrm{mV}$, activity of PS and $\mathrm{ASC}_{\mathrm{E}}$ in the same microcircuit increased slightly.

IPS neurons are nonspiking, so to test for a direct connection between IPS and $\mathrm{ASC}_{\mathrm{E}}$, we injected short current pulses to depolarize first IPS and then $\mathrm{ASC}_{\mathrm{E}}$, and recorded the other neuron's responses. Every depolarization of IPS immediately caused a hyperpolarization of $\mathrm{ASC}_{\mathrm{E}}$ 's membrane potential. The delay between the stimulus and response was $3.3 \pm 0.3 \mathrm{~ms}$ (Fig. $3 \mathrm{Bi}$ ). Additionally, each hyperpolarization of IPS immediately depolarized the membrane of $\mathrm{ASC}_{\mathrm{E}}$, with a delay of $3.2 \pm 0.4 \mathrm{~ms}$ (Fig. $3 \mathrm{Bii}$ ). We interpret these brief delays in the postsynaptic responses to mean that IPS neurons inhibited $\mathrm{ASC}_{\mathrm{E}}$ directly. The observation of a slight postsynaptic depolarization in response to presynaptic hyperpolarization is consistent with this connection being made by a graded inhibitory synapse that is partially active at the holding potential of $-60 \mathrm{mV}$ (Burrows, 1979). In contrast, depolarization of $\mathrm{ASC}_{\mathrm{E}}$ had no effect on IPS's membrane potential (data not shown). In summary, IPS neurons directly inhibit $\mathrm{ASC}_{\mathrm{E}}$ neurons, but since no reciprocal connection could be identified in these same recordings, we conclude that $\mathrm{ASC}_{\mathrm{E}}$ does not synapse onto IPS (Fig. 3C).

Additional support for this conclusion comes from changes in ASC $_{\mathrm{E}}$ 's input resistance $\left(R_{\text {in }}\right)$ at different phases in each cycle of 
$\mathrm{A} i$
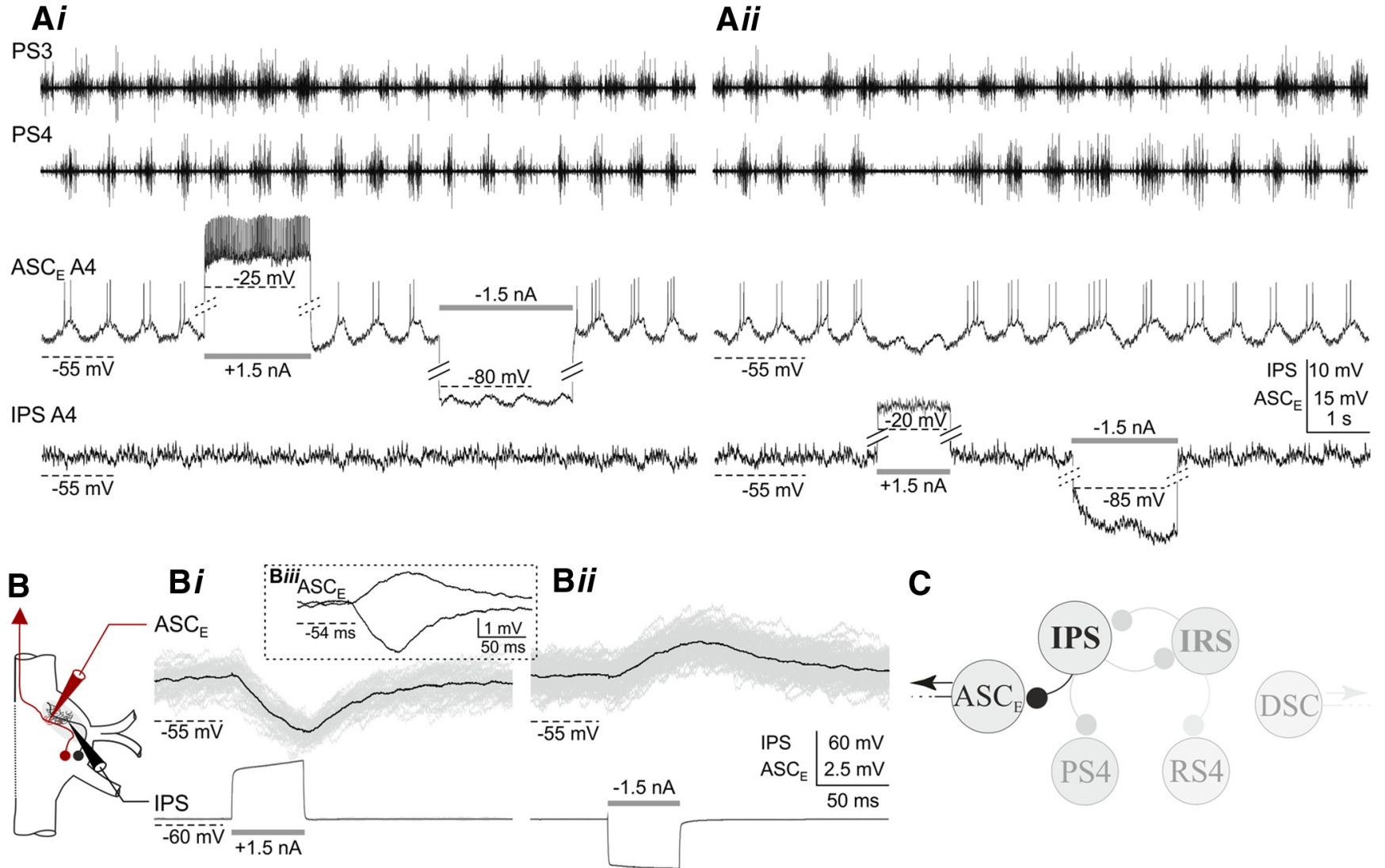

Bii

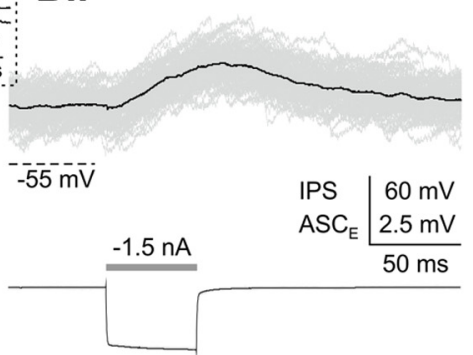

Dii
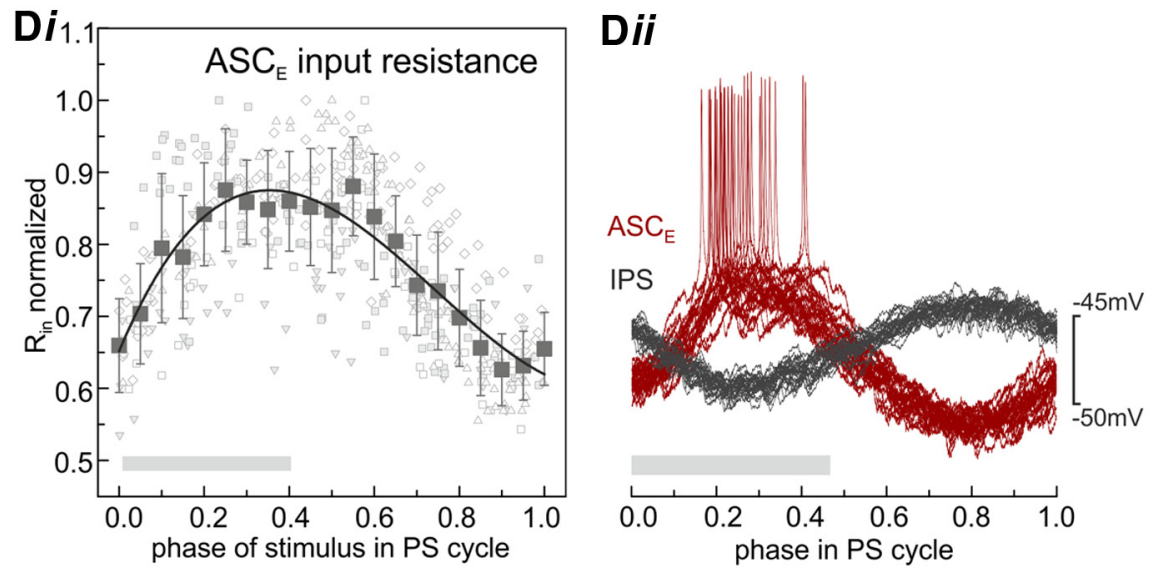

C
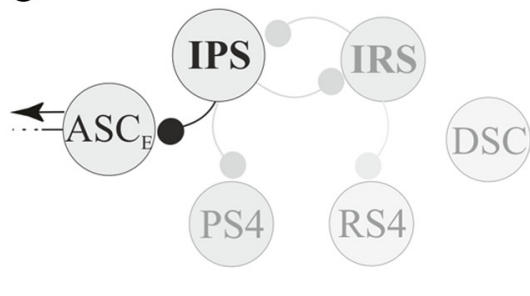

Figure 3. Simultaneous intracellular recordings of $\mathrm{ASC}_{\mathrm{E}}$ and IPS neurons. $A$, Traces from top to bottom, Extracellular recording of PS in ganglion $\mathrm{A} 3$ (PS3) and A4 (PS4), intracellular recordings of $\mathrm{ASC}_{\mathrm{E}}$ and IPS, both in $\mathrm{A4}$. Ai, ASC $\mathrm{E}$ depolarization and hyperpolarization, gray bar $( \pm 1.5 \mathrm{nA})$, affected only the target PS3, but not IPS or its own microcircuit. Aii, IPS depolarization and hyperpolarization, $\operatorname{gray}$ bar $( \pm 1.5 \mathrm{nA})$, affected the $\mathrm{PS}$ activity of its own microcircuit and changed $\mathrm{ASC}_{\mathrm{E}}$ activity. $\boldsymbol{B}$, The $50 \mathrm{~ms}$ long current pulses injected into IPS affected the membrane potential of $\mathrm{ASC}_{\mathrm{E}}$. Here, $>50$ traces were overlaid (gray), with the average potential superimposed in black. Bi, IPS depolarization $(+1.5 \mathrm{nA})$ immediately (delay of $3.3 \pm 0.3 \mathrm{~ms}$ ) hyperpolarized the ASC membrane potential. Bii, IPS hyperpolarization ( $-1.5 \mathrm{nA}$ ) immediately (delay of $3.2 \pm 0.4 \mathrm{~ms}$ ) depolarized the $\mathrm{ASC}_{\mathrm{E}}$ membrane potential. Biii, Comparison between the two responses in $\mathrm{ASC}_{\mathrm{E}}$. $C_{\text {, }}$ Circuit diagram of one microcircuit. ASC activity is controlled by direct inhibition from the IPS interneuron. Di, Plot of the ASC $_{\mathrm{E}}$ input resistance $\left(R_{i n}\right)$ measured during an ongoing rhythm (normalized, $N=5$ expts.). Gray bar represents the average PS burst duration. $R_{i n}$ maxima are found at the end of the PS burst, $R_{i n}$ minima at the beginning of the PS burst. Dii, Comparison of membrane potential oscillation of $\mathrm{ASC}_{\mathrm{E}}$ and IPS, recorded in two different experiments. Here $20 \mathrm{ASC}_{\mathrm{E}}$ (red) and 20 IPS (gray) traces were superimposed while their cycle period was normalized (gray bar represents the average PS burst duration).

activity (Fig. 3D). The median $R_{\text {in }}$ in $\mathrm{ASC}_{\mathrm{E}}$ was $13.5 \mathrm{M} \Omega$ (ranging from 7.2 to $22.2 \mathrm{M} \Omega, N=5$ expts.). During normal cyclic motor activity, $R_{\text {in }}$ changed as a function of phase (Fig. 3Di). The highest $R_{\text {in }}$ occurred at the end of each PS burst, near a phase of 0.5 , and the lowest $R_{\text {in }}$ occurred near a phase of $0 / 1$ when each PS burst was about to begin (Fig. 3Di,Dii, gray bar). Because the low $R_{i n}$ conditions occurred when IPS neurons were depolarized (Figs. $2 \mathrm{C}, 3 \mathrm{Dii})$, these fluctuations were probably due to periodic changes in an inhibitory synaptic conductance. These changes in
$\mathrm{ASC}_{\mathrm{E}}$ 's $R_{i n}$ with phase match the changes in $R_{i n}$ that occur at the same phases in PS excitatory neurons (Mulloney, 2003; Tschuluun et al., 2009), which strengthens the argument that $\mathrm{ASC}_{\mathrm{E}}$ and PS excitatory neurons are driven by parallel synapses from IPS.

\section{Working range of the IPS to $\mathrm{ASC}_{\mathrm{E}}$ synapse}

The membrane potential of IPS neurons oscillated in phase with the microcircuit's motor output; IPS was maximally hyperpolarized when PS motor neurons were firing and maximally depolar- 


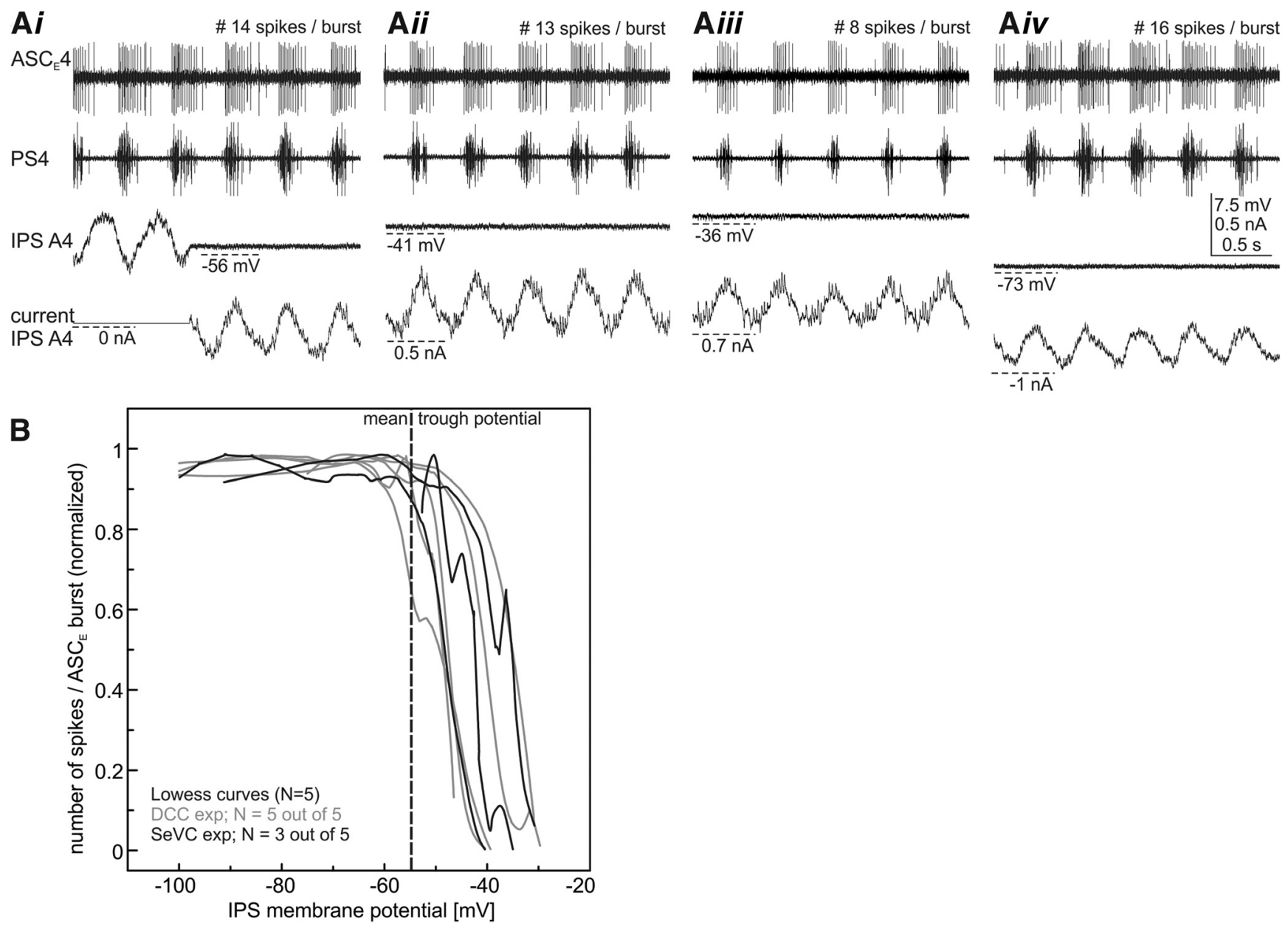

Figure 4. IPS potential controls $A S_{E}$ activity. $A$, Extracellular recordings of $\mathrm{ASC}_{\mathrm{E}} 4$ and PS4 together with the intracellular recording of IPS in $\mathrm{A} 4$ (voltage and current trace). IPS was recorded in

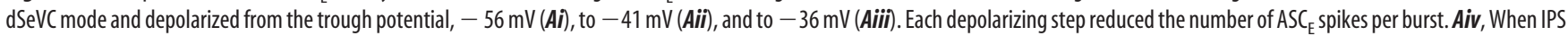
was hyperpolarized to $-73 \mathrm{mV}$ the number of $\mathrm{ASC}_{\mathrm{E}}$ spikes per burst increased. $\boldsymbol{B}$, The normalized numbers of $\mathrm{ASC}_{\mathrm{E}}$ spikes per burst were plotted as functions of the IPS holding potential. In five of five experiments, IPS was recorded in DCC mode, and in three of these five experiments in $\mathrm{ASEVC}$ mode. ASC $\mathrm{E}_{\mathrm{E}}$ spikes per burst in each experiment were smoothed with a robust Lowess protocol. In all experiments, the number of $\mathrm{ASC}_{\mathrm{E}}$ spikes per burst remained similar when IPS membrane potential was between $-100 \mathrm{mV}$ and the mean trough potential of $-55.7 \pm 4.5 \mathrm{mV}$. From approximately -55 to $-30 \mathrm{mV}$ the numbers of spikes per burst decreased monotonically.

ized during the intervals between PS bursts (Fig. 2C). We measured the "trough" potential, the maximum hyperpolarization, and the size of oscillations when no current was injected (Fig. $2 A i, B$ ). The mean IPS trough potential was $-55.7 \pm 4.5 \mathrm{mV}$ $(N=9$ expts.) ranging from -46.2 to $-64.3 \mathrm{mV}$. The mean amplitude of these IPS oscillations was $6.25 \pm 1.9 \mathrm{mV}(N=9$ expts.), ranging from 3.3 to $10.3 \mathrm{mV}$.

In active preparations, IPS was held at different potentials using either dSeVC or DCC while we recorded $\mathrm{ASC}_{\mathrm{E}}$ 's and PS's activity extracellularly from the same microcircuit. Upon depolarization of IPS, ASC $_{\mathrm{E}}$ and PS activity diminished (Fig. 4Ai-Aiii), while during hyperpolarization of IPS, $\mathrm{ASC}_{\mathrm{E}}$ and PS activity increased (Fig. 4Aiv). In five of five experiments, IPS was recorded in DCC mode, and in three of these five experiments also in $\mathrm{dSeVC}$ mode. In every experiment in which IPS was held at a range of different potentials (from -100 to $-30 \mathrm{mV}$ ), the same changes in $\mathrm{ASC}_{\mathrm{E}}$ 's activity were observed (Fig. $4 B$ ). In every experiment the number of $\mathrm{ASC}_{\mathrm{E}}$ spikes per burst did not change when IPS's membrane was hyperpolarized to between -100 and $-55 \mathrm{mV}$ (the mean trough potential). When the same IPS neuron's potential was depolarized to between -55 and $-30 \mathrm{mV}$, the firing of $\mathrm{ASC}_{\mathrm{E}}$ changed monotonically. It was remarkable that the threshold for change occurred reliably near an IPS membrane potential of $-55 \mathrm{mV}$, which is the mean trough potential of this interneuron. This implies that the periodic changes in inhibition of $\mathrm{ASC}_{\mathrm{E}}$ are most effective when IPS oscillates just above its threshold for transmitter release.

In every experiment, the greatest changes observed were in the duration and number of $\mathrm{ASC}_{\mathrm{E}}$ spikes per burst (Fig. $4 B$ ). Figure 5 shows the details of one experiment; the others showed the same phenomena. Both the number of spikes per $\mathrm{ASC}_{\mathrm{E}}$ burst and duration of these bursts began to roll off smoothly as IPS was depolarized above $-55 \mathrm{mV}$, and were completely inhibited by -35 $\mathrm{mV}$ (Fig. $5 A i, B i)$. The spike frequency within each $\mathrm{ASC}_{\mathrm{E}}$ burst (Fig. 5Ci) did not show a similar monotonic change. Rather, at some point between -40 and $-30 \mathrm{mV}$, the frequency crashed abruptly from $\sim 60$ to $0 \mathrm{~Hz}$ (Fig. 5Cii). In two of five experiments, independent of whether recording was performed in $\mathrm{dSeVC}$ or DCC mode, the period of the system's cycles changed from $0.57 \pm 0.03$ to $0.41 \pm 0.00 \mathrm{~s}$ (equivalent to a $25-27 \%$ change) when IPS was held at different potentials. In three other experiments the mean period $(0.51 \pm 0.03 \mathrm{~s})$ did not change signifi- 

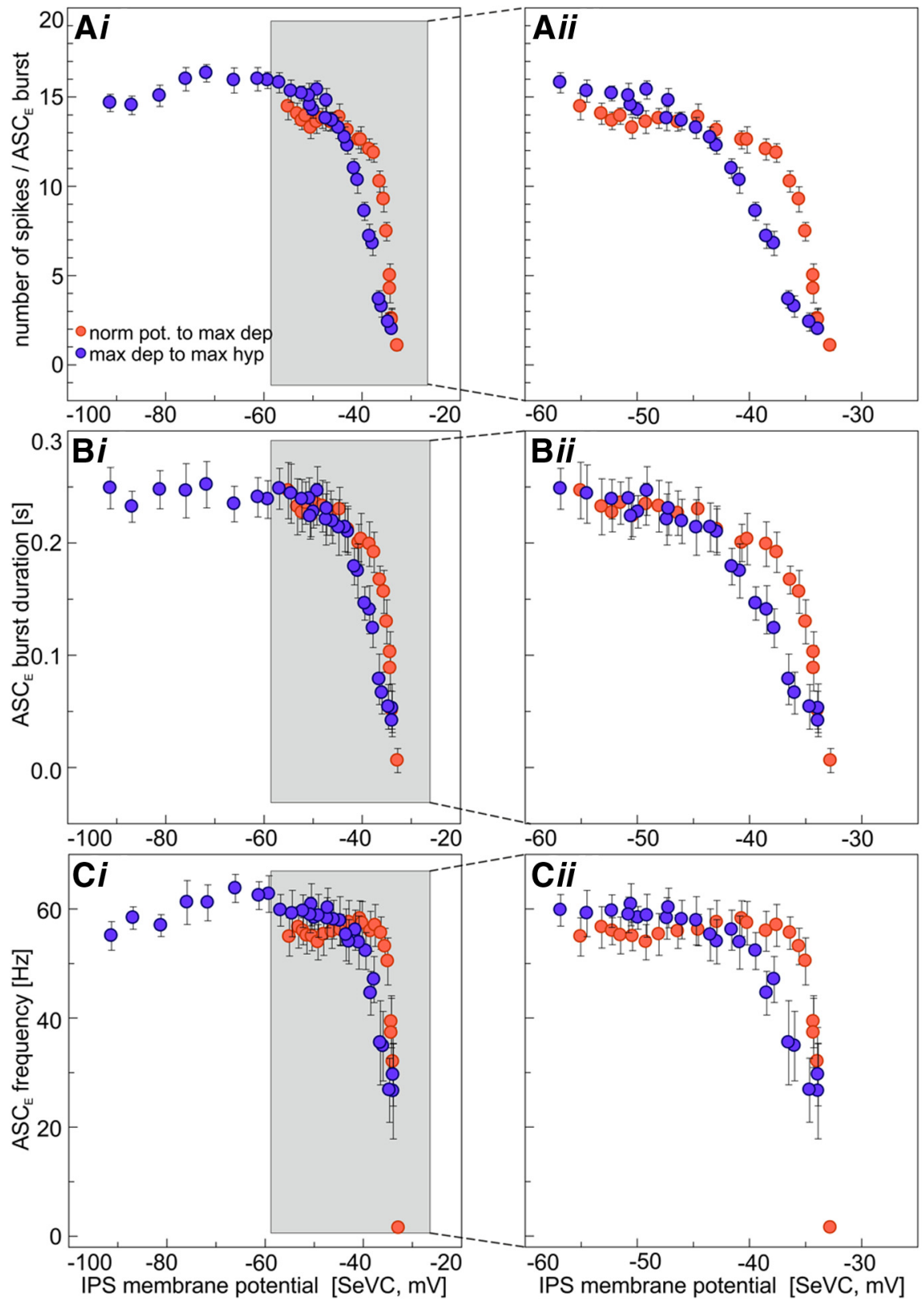

Figure 5. IPS membrane potential controls different $\mathrm{ASC}_{\mathrm{E}}$ parameters; IPS was recorded in dSeVC mode. Red dots, IPS was depolarized in $1 \mathrm{mV}$ steps from the trough potential $(-55 \mathrm{mV}$ ) to the maximal depolarized state $(-30 \mathrm{mV})$. Blue dots, IPS was repolarized in $1 \mathrm{mV}$ steps from the most depolarized membrane state $(-30 \mathrm{mV})$ to the maximal hyperpolarized state $(-100 \mathrm{mV})$. For each IPS potential the numbers of $\mathrm{ASC}_{\mathrm{E}}$ spikes per burst (Ai), burst duration $(\boldsymbol{B i})$, and spike frequency within bursts $(\boldsymbol{C} \boldsymbol{i})$ were measured for at least 15 bursts. The means $\pm S D$ were plotted as functions of IPS potential. Monotonic changes in the numbers of $\mathrm{ASC}_{\mathrm{E}}$ spikes per burst (Aii) and burst duration (Bii) were observed in the expansions from -55 to $-25 \mathrm{mV}$. Hysteresis between the depolarizing and repolarizing epochs of this experiment was also apparent. $C$, An abrupt change in spike frequency was observed during increasing depolarization (expanded in Cii).

cantly ( $0.46 \pm 0.06 \mathrm{~s}$; equivalent to a $4-12 \%$ change), but compared with changes in the other parameters these changes in period were minor.

In experiments in which the presynaptic IPS neuron was held at each step for $>30$ cycles, between 15 and 20 s, the effectiveness of inhibition showed clear hysteresis (Fig. 5Aii,Bii,Cii). At each holding potential, the extent of inhibition was greater when the neuron had previously been more depolarized (blue dots) than it was when the neuron had previously been more hyperpolarized (red dots). In all cases, $\mathrm{ASC}_{\mathrm{E}}$ 's activity did not drop as rapidly when IPS was being slowly depolarized (Fig. 5Aii,Bii,Cii, red dots), and $\mathrm{ASC}_{\mathrm{E}}$ activity did not recover as fast when IPS was being slowly repolarized (Fig. 5Aii,Bii,Cii, blue dots). Thus, the previous state of IPS affected the strength of its inhibition of $\mathrm{ASC}_{\mathrm{E}}$.

\section{How reliable is encoding by $\mathrm{ASC}_{\mathrm{E}}$ ?}

In these voltage-clamp experiments, we simultaneously recorded PS firing, which enabled us to calculate the strengths of each PS and $\mathrm{ASC}_{\mathrm{E}}$ burst and examine the covariation of these measurements. Plotting $\mathrm{ASC}_{\mathrm{E}}$ burst strength as a function of PS burst strength revealed a strong linear correlation between these parameters (Fig. 6). The correlation coefficients, $R$, of these strengths were $\geq 0.81$ ( $N=5$ expts.). The number of $\mathrm{ASC}_{\mathrm{E}}$ spikes per burst and duration of $\mathrm{ASC}_{\mathrm{E}}$ bursts were also strongly correlated with PS burst strength ( $R \geq 0.85, N=5$ expts.; data not shown). So, as IPS inhibition of $\mathrm{ASC}_{\mathrm{E}}$ increased (Fig. 5), PS was also inhibited, and the bursts of $\mathrm{ASC}_{\mathrm{E}}$ spikes continued to be an accurate efference copy of PS motor output.

\section{Do these changes in $\mathrm{ASC}_{\mathrm{E}}$ bursts affect} microcircuits in other segments?

$\mathrm{ASC}_{\mathrm{E}}$ axons project anteriorly to targets in each more anterior ganglion (Fig. 1), and perturbations of the timing or strength of $\mathrm{ASC}_{\mathrm{E}}$ bursts are known to affect the phases of PS bursts originating in these more anterior ganglia (Mulloney and Hall, 2007). During these voltage-clamp experiments, we simultaneously recorded PS firing in ganglia both anterior and posterior to the one where IPS was recorded. We compared variations in PS burst strength in these neighboring ganglia (Fig. 7Aii,Aiii,Bii,Biii) with PS strengths in the microcircuit where IPS's potential was held at different potentials (Fig. $7 \mathrm{Ai}, \mathrm{Bi}$ ). When IPS was held at potentials anywhere from -100 to $-55 \mathrm{mV}$, PS burst strengths did not vary significantly in either ganglion. However, as IPS was depolarized above $-55 \mathrm{mV}$, the strengths of PS bursts in more anterior ganglia also decreased monotonically (Fig. 7Aii,Bii). In interpreting these results, it is important to recall that each swimmeret hemiganglion has its own set of PS motor neurons, that all the motor axons in each $\mathrm{N} 1$ originate from neurons in one hemisegment, and that motor neurons do not project axon collaterals to other segments (Mulloney and Hall, 2000). Therefore, the most probable mechanism for the intersegmental effects caused by changing one IPS neuron's potential is that correlated changes in the strengths of $\mathrm{ASC}_{\mathrm{E}}$ bursts (Figs. 5, 6) are integrated in the more anterior ganglia by $\mathrm{Co}-$ mIntl neurons and conducted to the kernel of the more anterior microcircuit (Smarandache-Wellmann et al., 2014), altering the strength of that microcircuit's PS bursts. 


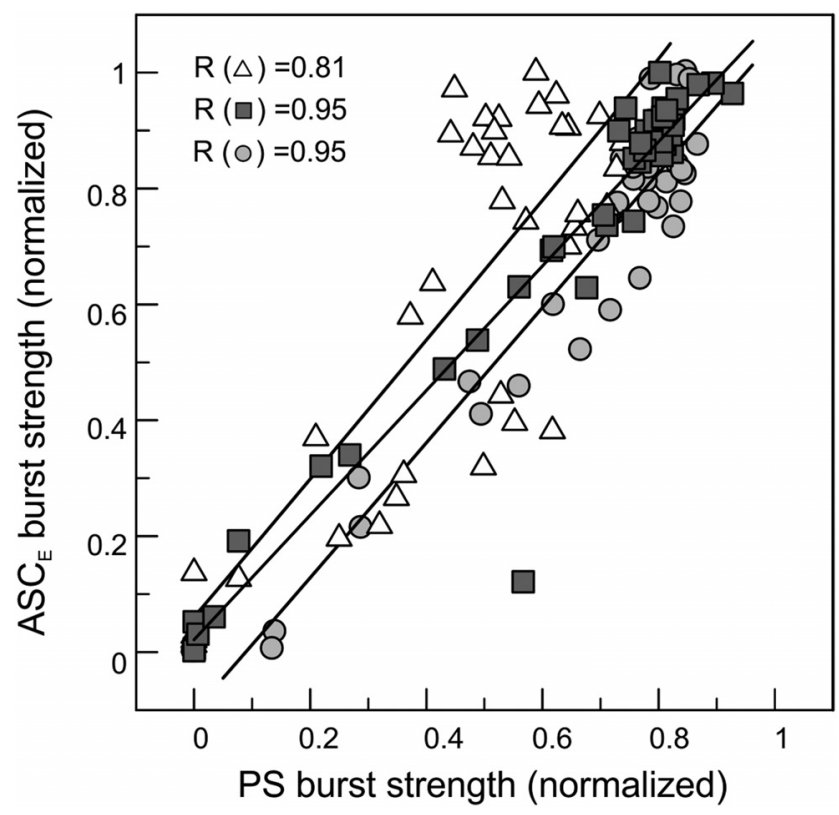

Figure 6. Plot of the linear correlation between PS burst strength and $\mathrm{ASC}_{E}$ burst strength in the same microcircuit ( $N=3$ expts.).

The axons of $\mathrm{ASC}_{\mathrm{E}}$ neurons do not project posteriorly, so it is surprising that the strengths of PS bursts in more posterior ganglia were also affected by changes in an IPS's membrane potential (Fig. 7Aiii,Biii). Just as PS bursts in more anterior ganglia were unaffected by holding IPS anywhere between -100 to $-55 \mathrm{mV}$, the more posterior ganglia were similarly unaffected. However, as IPS was depolarized above $-55 \mathrm{mV}$, the strengths of PS bursts in more posterior ganglia increased (Fig. 7Aiii,Biii). In the chain of swimmeret microcircuits (Fig. 1), coordinating information is conducted to more posterior segments by axons of DSC neurons, originating in A2, A3, and A4 (Namba and Mulloney, 1999; Smarandache et al., 2009). Simultaneous recordings of an IPS neuron and the DSC neurons in the same microcircuit showed that DSC activity changed when IPS was held at different potentials (Fig. 8). When IPS was depolarized, DSC firing increased (Fig. $8 C ; N=3$ ). The same manipulation increased PS bursts in more posterior segments (Fig. 7Aiii,Biii), which suggests that these posterior increases are caused by these increasingly strong DSC bursts. DSC affects neighboring circuits through the same target neurons as $\mathrm{ASC}_{\mathrm{E}}$ affects the anterior microcircuits, but DSC fires in antiphase with PS and $\mathrm{ASC}_{\mathrm{E}}$ and affects only the posterior microcircuits.

\section{Inhibition by nonspiking IRSh interneurons shapes bursts in DSC coordinating neurons}

Because each DSC fires simultaneously with the RS motor neurons in the same microcircuit and encodes information about RS bursts (Mulloney et al., 2006), we hypothesized that DSC is inhibited by IRS neurons in the microcircuit's pattern-generating kernel (Fig. 1C). Intracellular recording of IRS is difficult and many times the rhythm stops when the dendrites of this neuron are penetrated with sharp electrodes. Therefore we used a disynaptic pathway to study this inhibition.

Each microcircuit includes two types of IRS neurons in its pattern-generating kernel (Smarandache-Wellmann et al., 2013). ComInt1 (Fig. 9A), the target of DSC axons in each ganglion, is electrically coupled to one of these IRS neurons, IRSh (Smarandache-Wellmann et al., 2014). We used this disyn- aptic pathway-ComInt1 to IRSh to DSC - to study this inhibition (Fig. 9C). We recorded simultaneously from ComInt1 intracellularly using DCC mode and from DSC using an extracellular suction electrode (Fig. 9B). When ComIntl was depolarized, DSC spiking activity decreased. When ComInt1 was hyperpolarized, DSC activity increased until all PS bursting stopped and DSC fired tonically (Fig. 9D; $N=8$ expts.). Because ComInt1 is electrically coupled to IRSh, these results are consistent with the hypothesis that IRSh shapes DSC activity through an inhibitory synapse (Fig. 9C).

To map the working range of this disynaptic connection, we used DCC mode to hold ComIntl at a series of potentials between -100 and $-10 \mathrm{mV}$, and recorded DSC bursts $(N=5$ expts.). We analyzed the duration and the number of spikes per DSC burst, spike frequency within each burst, and the period of the motor pattern. From approximately -60 to $-10 \mathrm{mV}$, the numbers of spikes per DSC burst and the durations of these bursts decreased steadily (Fig. 9Ei,Eii). The frequency of firing (normalized to compare between different preparations) within these bursts increased steadily from approximately -90 to -20 $\mathrm{mV}$ (Fig. 9Eiii), which suggests that the decreasing numbers of spikes per burst at depolarized potentials were caused by decreasing burst durations. Periods did not change with ComInt1 membrane potential (data not shown; Smarandache-Wellmann et al., 2014).

These results yield an interpretation of the different responses of anterior and posterior microcircuits to depolarization of an IPS neuron (Fig. 7). IPS neurons are part of the patterngenerating kernel of each microcircuit (Fig. 1C) and when they are increasingly depolarized, they increase their inhibition not only of PS and $\mathrm{ASC}_{\mathrm{E}}$ neurons but also of their IRS antagonists in the kernel. This inhibition weakens the periodic inhibition of RS neurons and of DSC by IRS neurons, so DSC neurons fire stronger bursts (Fig. 8). These strengthened DSC bursts cause larger periodic depolarizations of the ComInt1 neurons in more posterior microcircuits. These periodic depolarizations are timed to increase IRSh's periodic inhibition of IPS neurons within each kernel, and thereby weaken periodic inhibition of these posterior microcircuit's PS bursts.

\section{Discussion}

This set of experiments demonstrates that perturbations of one of the key nonspiking interneurons in one of a chain of distributed microcircuits can affect neighboring microcircuits and thus affect coordination of the movements these microcircuits control. These intersegmental effects follow from three factors: reliable encoding of efference copies of the perturbed microcircuit's activity by $\mathrm{ASC}_{\mathrm{E}}$ and DSC neurons, the timing of bursts of spikes in these coordinating neurons, and integration of the information they conduct into the ongoing activities of other microcircuits in the chain (Smarandache-Wellmann et al., 2014).

\section{How these synaptic connections enable precise efference copies of motor output}

$\mathrm{ASC}_{\mathrm{E}}$ neurons are able to encode details of each burst of spikes in their microcircuit's PS motor neurons because they are inhibited by the same interneurons, IPS (Fig. 3), which sculpt each PS burst. IPS neurons also inhibit IRS neurons, and are in turn inhibited by IRS neurons. This reciprocal inhibition forms a synaptic circuit that generates alternating oscillations of their membrane potentials when these neurons are above threshold for transmitter release (Perkel and Mulloney, 1974; Wang and Rinzel, 1992; Skinner et al., 1994). These oscillations of potential 
A

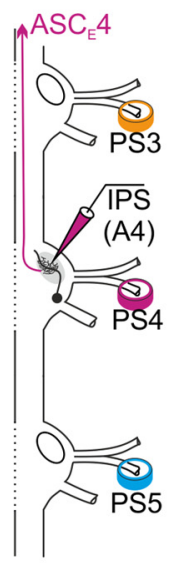

B

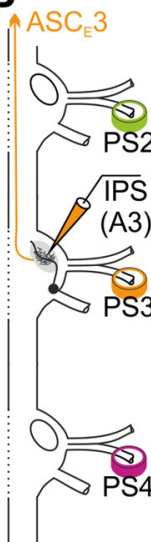

microcircuit where IPS potential was modified:
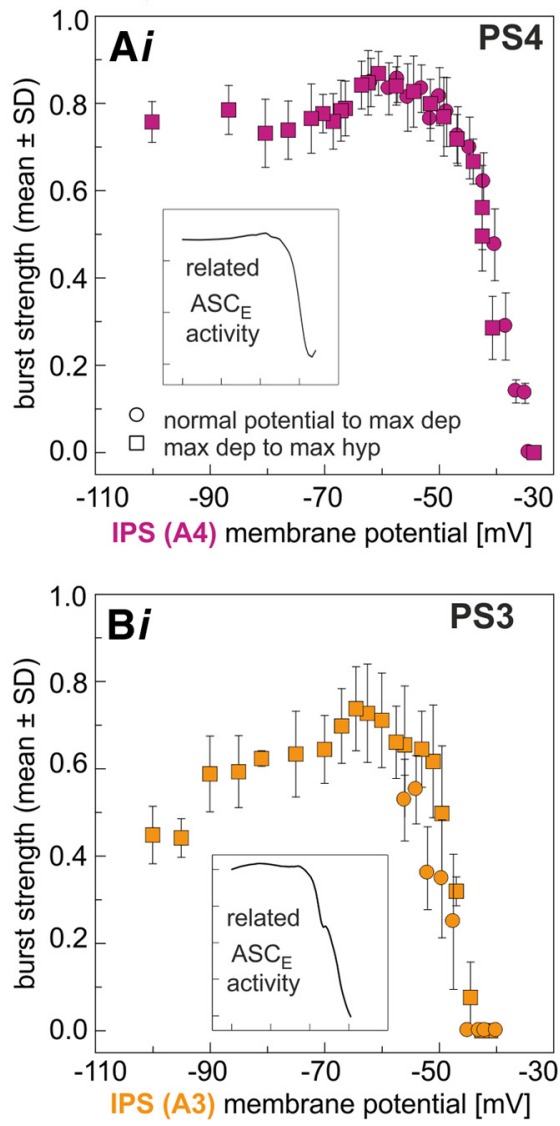

microcircuit anterior to perturbation:
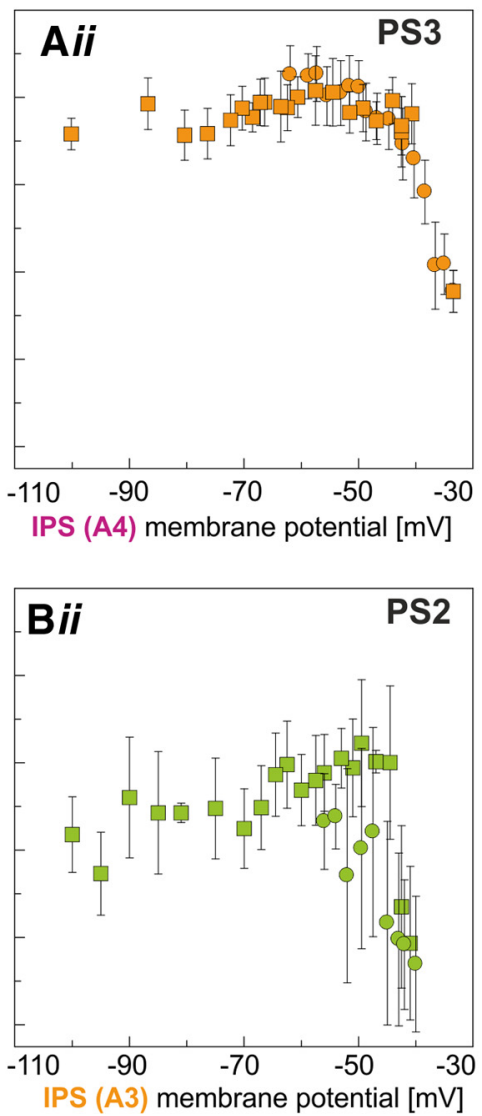

microcircuit posterior to perturbation:
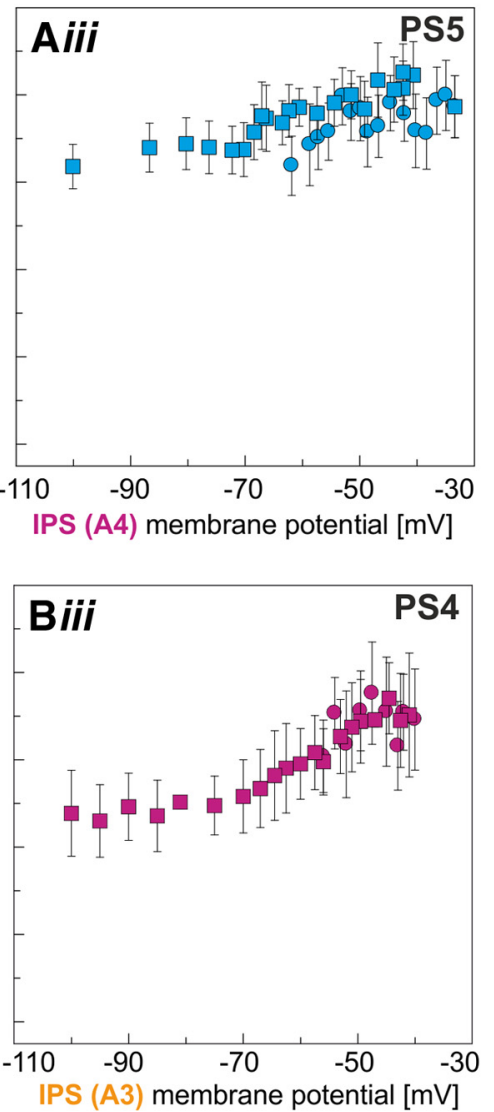

Figure 7. Changing IPS membrane potential in one segment influenced PS burst strength in its own microcircuit and in microcircuits in adjacent segments. Examples are from two different experiments $(\boldsymbol{A}, \boldsymbol{B})$. Colors mark the segment where recordings were made (as per Fig. 1). $\boldsymbol{A}$, IPS was recorded in A4. Burst strengths of PS4, PS3 (anterior to perturbation), and PS5 (posterior to perturbation) were measured and plotted as functions of IPS potential in A4. B, IPS was recorded in A3. Burst strengths of PS3, PS2 (anterior to perturbation), and PS4 (posterior to perturbation) were measured and plotted as functions of the IPS holding potential in A3. Ai, Bi, IPS potential affected PS burst strength in the home segment in the same way that it affected ASC $\mathrm{E}_{\mathrm{E}}$ activity (see inset). The strongest, monotonic change was observed when IPS was depolarized from $-55 \mathrm{mV}$ up to $-30 \mathrm{mV}$. There was no change in PS burst strength when IPS was hyperpolarized beyond $-55 \mathrm{mV}$. Aii, Bii, The microcircuit anterior to the clamped IPS neuron received altered ASC $_{E}$ information. The strengths of PS bursts in the anterior microcircuit plotted as functions of the IPS potential from the posterior ganglion followed a similar monotonic decline as the curves in Aiand Bi. Aiii, Biii, Microcircuits posterior to the clamped IPS neuron also changed the strengths of PS bursts, but in a different way. In these posterior microcircuits, PS burst strength remained steady from -100 to $-65 \mathrm{mV}$ of IPS potential in the anterior ganglion, but PS burst strength increased as IPS was depolarized above $-65 \mathrm{mV}$.
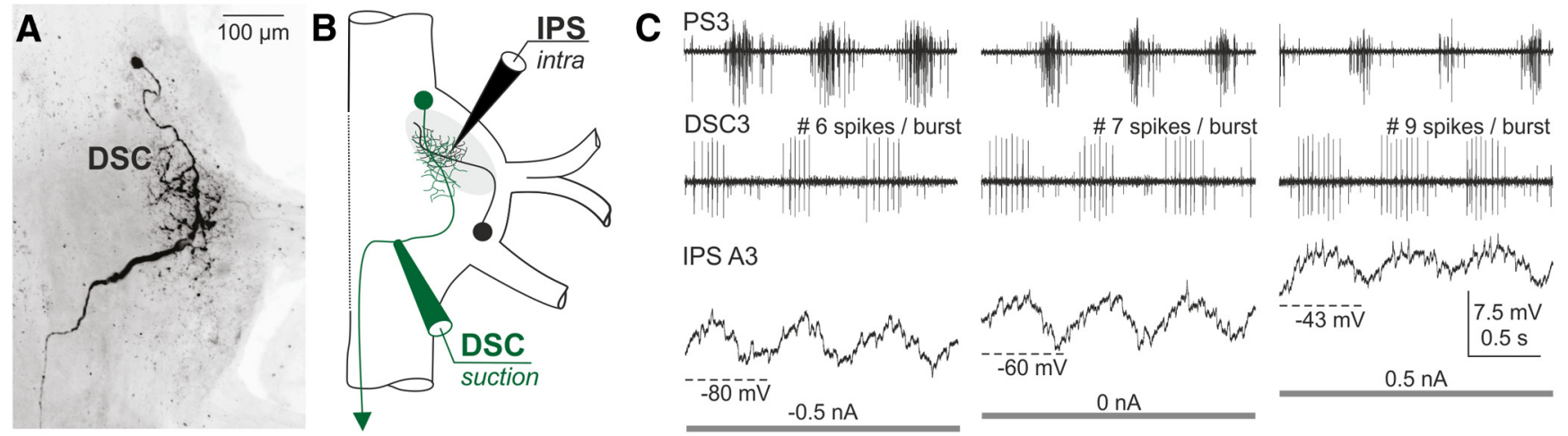

IPS A3

Figure 8. IPS membrane potential also affects DSC activity. $\boldsymbol{A}$, Whole mount of one abdominal hemiganglion, seen from the dorsal side. DSC is filled with dTR. $\boldsymbol{B}$, Diagram of electrode placement in this experiment. IPS was recorded intracellularly with sharp microelectrodes in the LN, while DSC was recorded extracellularly with a suction electrode, placed on the posterior MnT where DSC's axon passes dorsally to the LG. C, Effect of IPS on DSC and PS activity in the same microcircuit. The three traces from top to bottom, Extracellular recordings of PS and DSC, and an intracellular recording of IPS. When IPS was hyperpolarized to $-80 \mathrm{mV}$ (current injection of $-0.5 \mathrm{nA}$ ), the number of DSC spikes per burst dropped compared with the control (when no current was injected). During depolarization, DSC activity increased. The effect observed in Figure 7Aiii and Biii resulted from this change in the activity of the coordinating neuron DSC, which projects to posterior modules. 
A
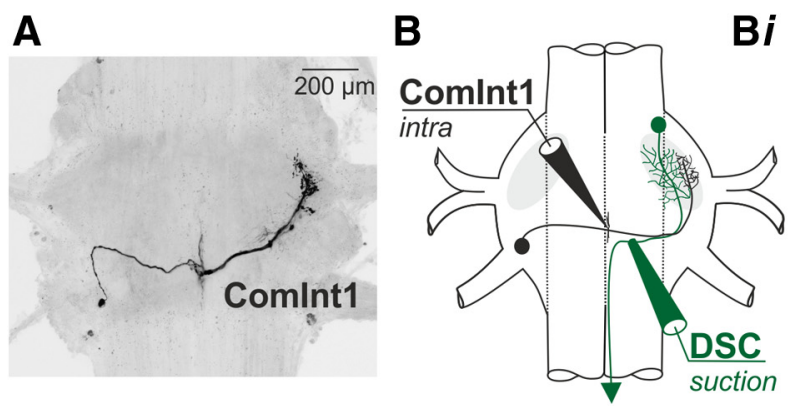

Bi

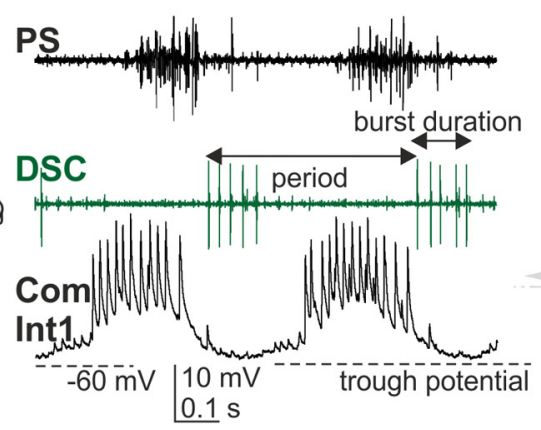

C

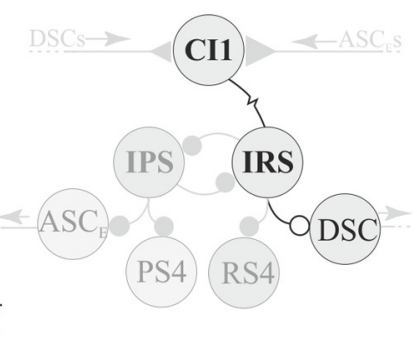

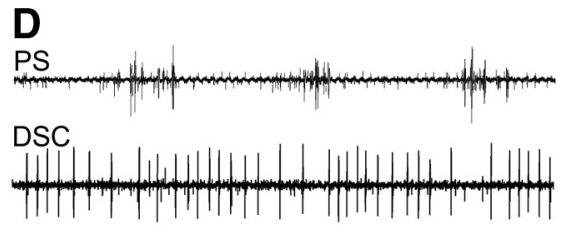
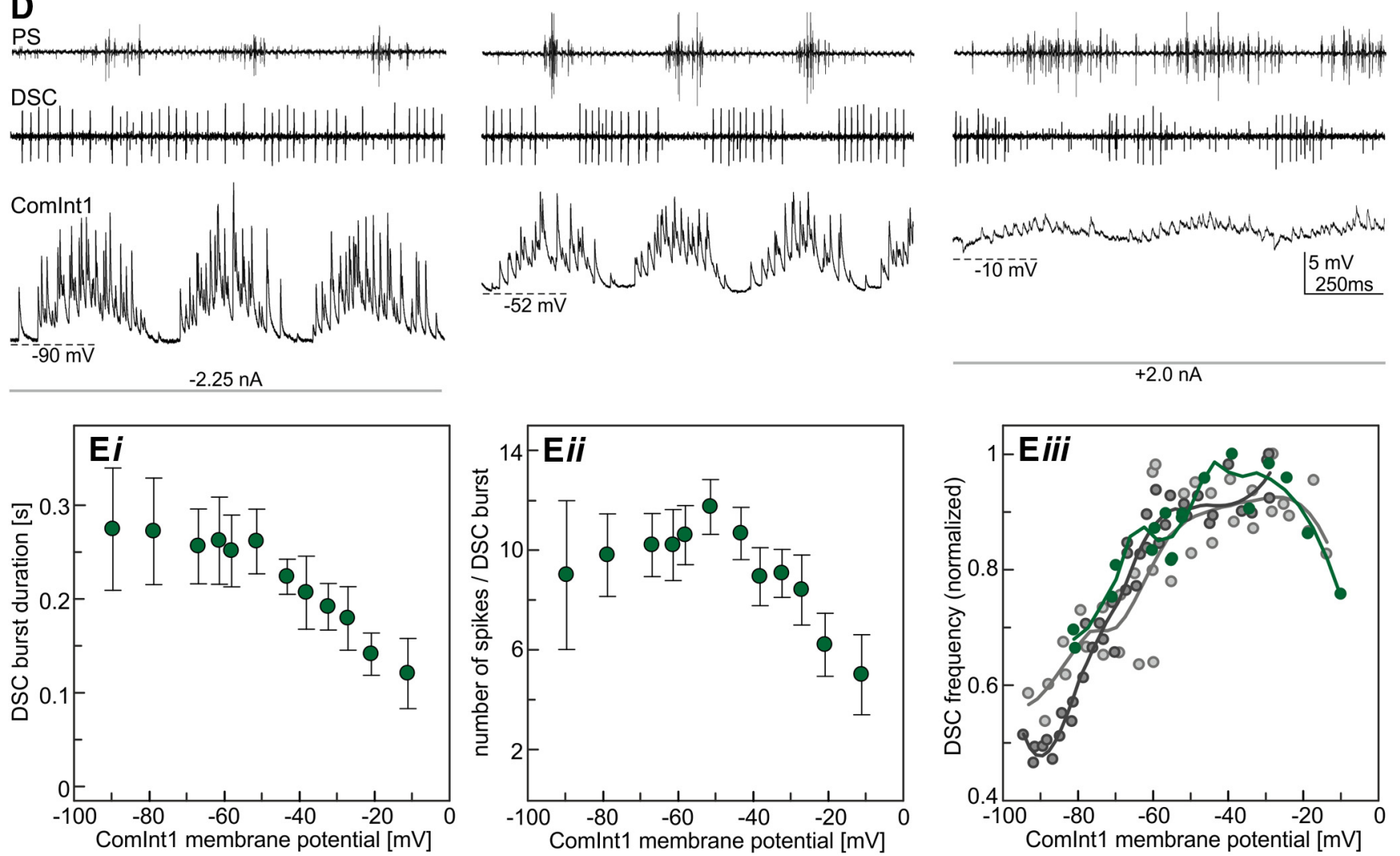

Figure 9. Comlnt1 membrane potential influences DSC activity. A, Whole-mount preparations of one abdominal ganglion, seen from the dorsal side. Comlnt1 is filled with dTR. $\boldsymbol{B}$, Diagram of the placement of the electrodes for this experiment. Comlnt1 (CI1) was recorded intracellularly with sharp microelectrodes at the midline, while DSC was recorded extracellularly with suction electrodes. Bi, Simultaneous extracellular recordings of PS and DSC and intracellular recording of Comlnt1, all from the same microcircuit. Parameters measured: period, duration of the DSC burst, and number of spikes per DSC burst. C, Schematic drawing of the connection in one microcircuit. A new synapse is postulated, the inhibitory synapse from IRS to DSC. D, When ComInt1 was hyperpolarized ( $-2.25 \mathrm{nA}$, gray bar), DSC activity increased and PS bursts weakened, compared with no current injection into ComInt1. During ComInt1 depolarization ( $+2 \mathrm{nA})$, PS bursts strengthened and DSC bursts were shorter with fewer spikes per burst. Traces from top to bottom: Extracellular recordings of PS and DSC, and an intracellular recording of ComInt1. E, DSC parameters affected by different holding potentials of ComInt1 (DCC-mode recordings). Burst duration (Ei) and number of spikes in each DSC burst (Eii) decreased with depolarization of Comlnt1 membrane potential. Eiii, DSC frequency was smallest during hyperpolarization of Comlnt1, and increased with a depolarized membrane potential of Comlnt1 (shown for $N=3$ expts.).

then tune these neurons' graded, inhibitory synapses onto motor neurons and so cause alternating bursts of PS and RS spikes (Mulloney, 2003; Tschuluun et al., 2009). The synapse from IPS onto $\mathrm{ASC}_{\mathrm{E}}$ is tuned in the same way as the IPS synapse onto PS motor neurons, so quantitative variations in IPS's membrane potentials are transmitted simultaneously to both postsynaptic targets and cause firing by both PS motor neurons and $\mathrm{ASC}_{\mathrm{E}}$ to vary simultaneously (Fig. 6).

The rates of information transmission at graded synapses can be very high (DiCaprio et al., 2007), but the sensitivity and precision of the IPS-ASC $\mathrm{E}_{\mathrm{E}}$ synapse is remarkable. In the middle of its working range, changes in presynaptic potential as small as $1 \mathrm{mV}$ caused measurable changes in PS strength (Fig. 7Ai,Bi) and reproducible one-spike changes in ASC $_{\mathrm{E}}$ bursts (Figs. $4 B, 5 A$ ).

DSC neurons respond to perturbations of both IPS and ComInt1 neurons (Figs. 8,9 ) as if they are also inhibited by the same interneurons, IRS, which sculpt each RS burst. This synapse from IRS onto DSC would also be tuned in the same way as IRS's synapses onto RS motor neurons, and would cause firing of both RS motor neurons and DSC to vary simultaneously. This quantitative covariation of bursts of spikes in coordinating neurons is the basis of the efference copies that permit the coordinating circuit (Fig. 10) to synchronize and stabilize the phases of swimmerets on different segments of the body. 


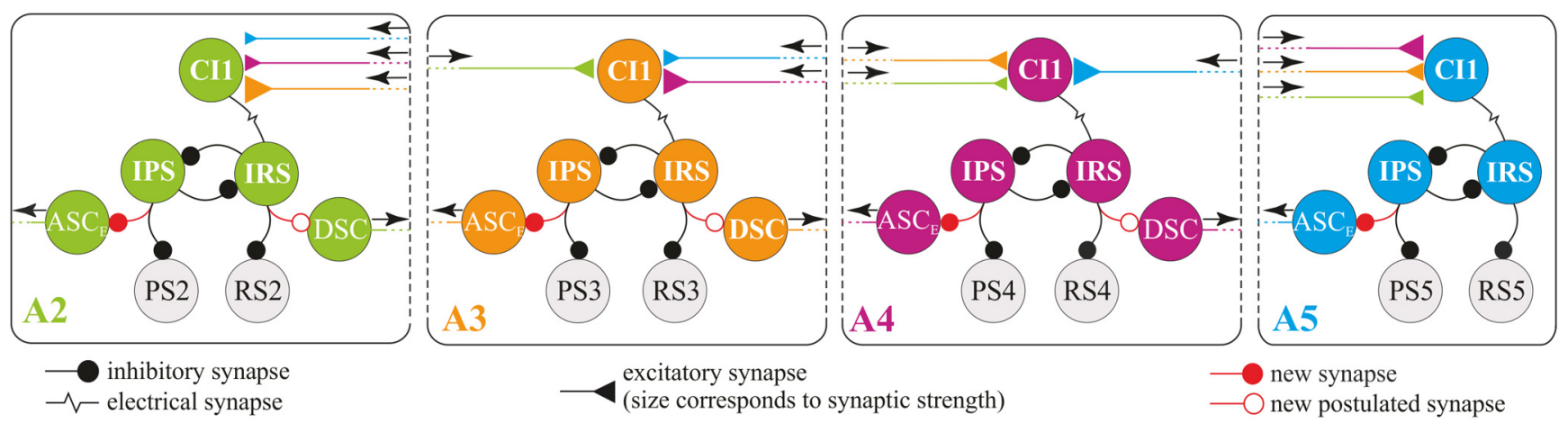

Figure 10. The synaptic organization of the intersegmental circuit that coordinates swimmeret microcircuits in ganglia $A 2$ to $A 5$. In each microcircuit, the coordinating information in $\mathrm{ASC}_{\mathrm{E}}$ and DSC is driven via direct inhibitory connection from the microcircuits pattern-generating kernel. IPS shapes $\mathrm{ASC}_{\mathrm{E}}$ activity through a direct inhibitory connection and we have strong evidence that IRS also shapes DSC activity through an inhibitory synapse. This new information, combined with the recently published results that Comlnt1 (CI1) transmits the coordinated information through an electrical synapse to an IRS neuron in the microcircuit's pattern-generating kernel, yields a new model of the system, depicted here. Symbols and colors are the same as Figure 1. Arrows indicate the direction of impulse traffic in coordinating axons and motor axons.

\section{The synaptic organization of the intersegmental coordinating circuit}

$\mathrm{ASC}_{\mathrm{E}}$ and DSC axons conduct information to each microcircuit in other segments as bursts of spikes. In those microcircuits, one commissural interneuron, ComInt1, integrates EPSPs from these efference copy axons and transmits it to an interneuron, IRSh (Fig. 1C), in the pattern-generating kernel of the microcircuit (Smarandache-Wellmann et al., 2013, 2014).

From these results and those in Smarandache-Wellmann et al. (2014), we propose a revised model of the swimmeret coordinating circuit (Fig. 10). The major changes from earlier models (Skinner and Mulloney, 1998; Smarandache et al., 2009; Mulloney and Smarandache-Wellmann, 2012) are the inhibitory synapses onto coordinating neurons that parallel synapses from pattern-generating interneurons onto motor neurons, and the electrical synapse between each ComInt1 neuron (Fig. 10, CI1) and the IRS neuron in its microcircuit. Previous models postulated that the critical synaptic drive to coordinating neurons was excitatory, but that was incorrect. In this model, ComInt1s serve as hub neurons integrating information of different kinds and linking each microcircuit into the coordinated system (Gutierrez et al., 2013; Smarandache-Wellmann et al., 2014). Each of the intersegmental connections in Figure 10 have been demonstrated experimentally.

With the intersegmental circuit these coordinating neurons and commissural neurons form, the system is able to keep a stable phase difference between neighboring circuits despite 10-fold changes in the frequency of the rhythm. This revised circuit accounts for synchronization of oscillations in different microcircuits in this way: in each microcircuit, $\mathrm{ASC}_{\mathrm{E}}$ and DSC neurons fire alternating bursts of spikes, simultaneously with PS and RS motor neurons (Fig. 1D). At the same time, the ComInt1 in each microcircuit receives simultaneous bursts of EPSPs from coordinating axons originating in other segments (Smarandache et al., 2009). Through their electrical synapse, these periodic bursts of EPSPs depolarize both ComInt1 and the IRSh neurons in the microcircuit's kernel (Smarandache-Wellmann et al., 2014). These periodic depolarizations entrain the oscillations of each microcircuit's kernel and synchronize the chain of microcircuits to the same period (Zhang and Lewis, 2013) and to a stable metachronal phase (Zhang et al., 2014).
Different responses of anterior and posterior microcircuits to depolarizing IPS neurons

Why does depolarizing an IPS neuron weaken PS bursts in more anterior segments but strengthen PS bursts from more posterior segments (Fig. 7)? Depolarizing an IPS neuron in one microcircuit weakens ASC $_{\mathrm{E}}$ bursts (Fig. 5) but strengthens DSC bursts (Fig. 8) originating in the same microcircuit. So, ComInt1 neurons in neighboring ganglia that are targets of these $\mathrm{ASC}_{\mathrm{E}}$ and DSC axons (Fig. 10) get opposite signals; the anterior ComInt1 is less depolarized but the posterior ComInt1 is more depolarized. Since each ComInt 1 is electrically coupled to the IRSh neuron in its microcircuit's pattern-generating kernel (SmarandacheWellmann et al., 2014), these differential changes in the two ComInt1s' potentials cause opposite changes in strengths of PS bursts in the anterior and posterior ganglia observed in Figure 7. Because ComInt1 and IRSh are both nonspiking neurons, these changes are proportional to changes in the strengths of bursts in these coordinating axons (Smarandache-Wellmann et al., 2014).

\section{Identified efference copy neurons in other systems}

The activity of efference copy neurons represents a copy of the efferent motor command that targets the muscles driving a movement (von Holst and Mittelstaedt, 1950; Crapse and Sommer, 2008). The presence of efference copy neurons that fire corollary discharges has been demonstrated in many systems and was analyzed in the focus of how it affects its targets (Bell, 1981; Poulet and Hedwig, 2003a,b, 2007; Ford and Mathalon, 2005; Chagnaud and Bass, 2013; von Uckermann et al., 2013). To our knowledge the work presented here is the first description of the synapses that control encoding by an efference copy neuron. The properties of these synapses help explain why $\mathrm{ASC}_{\mathrm{E}}$ and DSC are able to encode changes in motor output so precisely.

\section{Where else might we find coordinating circuits using the same principles?}

The results presented here demonstrate that pattern-generating neurons within each microcircuit tune the activity of efference copy neurons via similar synaptic connections as they make onto motor neurons. Swimmeret microcircuits are distributed as bilateral pairs in the chain of ganglia in abdominal segments that possess swimmerets. This distribution is similar to the segmental innervation of walking legs in insects (Büschges et al., 2011; Büschges and Borgmann, 2013), crustaceans (Cattaert et al., 
1995; Mulloney et al., 2003), amphibians (Ryczko et al., 2010; Bicanski et al., 2013), turtles (Stein, 2008), and mammals (Kiehn, 2006; Goulding, 2009; Hägglund et al., 2013). The segmental muscles used by fish for swimming and by leeches for swimming and crawling are also innervated by segmentally distributed neural microcircuits (Kristan et al., 2005; Grillner, 2006; Stein, 2008; Fetcho and McLean, 2010; Puhl and Mesce, 2010; Mullins et al., 2011; Bagnall and McLean, 2014). In all these nervous systems, the motor neurons and the premotor microcircuitry that drives locomotion are located close to the segmental or joint musculature that they control. Synchronization of the motor drive to different muscle groups or to different limbs requires mutual exchange of information between these microcircuits. Therefore in these segmentally distributed systems we can expect to find efference copy neurons like $\mathrm{ASC}_{\mathrm{E}}$ and DSC encoding details of each cycle of motor output, and hub neurons like ComInt1 in each segment decoding and integrating information from multiple sources.

A different mechanism of coordinating segmentally distributed muscles occurs in the innervation of leech heart and in control of vertebrate respiration (Lieske et al., 2000; Johnson et al., 2001; Masino and Calabrese, 2002; Gariépy et al., 2012; Cinelli et al., 2013). In these systems, the period of each cycle of movement is determined by a rhythm-generating circuit located in one or a few anterior segments, but the intersegmental coordination of contractions within the cycle is left to differences in strengths of synapses onto motor neurons in different segments (Wright and Calabrese, 2011). There is no feedback directly from the segmental level to the rhythm-generating circuit. However, efference copies and hub neurons might prove to be crucial for coordination of respiratory movements with other critical behaviors, e.g., the flexible phase-locking of whisking, sniffing, and ventilation that occurs in rodents (Moore et al., 2013).

\section{References}

Bagnall MW, McLean DL (2014) Modular organization of axial microcircuits in zebrafish. Science 343:197-200. CrossRef Medline

Bell CC (1981) An efference copy which is modified by reafferent input. Science 214:450-453. CrossRef Medline

Bicanski A, Ryczko D, Knuesal J, Harischandra N, Charrier V, Ekeberg Ö, Cabelguen JM, Ijspeert AJ (2013) Decoding the mechanisms of gait generation in salamanders by combining neurobiology, modeling and robotics. Biol Cybern 107:545-564. CrossRef Medline

Burrows M (1979) Synaptic potentials effect the release of transmitter from locust non-spiking interneurons. Science 204:81-83. CrossRef Medline

Büschges A, Borgmann A (2013) Network modularity: back to the future in motor control. Curr Biol 23:R936-R938. CrossRef Medline

Büschges A, Scholz H, El Manira A (2011) New moves in motor control. Curr Biol 21:R513-R524. CrossRef Medline

Cattaert D, Pearlstein E, Clarac F (1995) Cholinergic control of the walking network in the crayfish Procambarus clarkii. J Physiol Paris 89:209-220. CrossRef Medline

Chagnaud BP, Bass AH (2013) Vocal corollary discharge communicates call duration to vertebrate auditory system. J Neurosci 33:18775-18780. CrossRef Medline

Cinelli E, Robertson B, Mutolo D, Grillner S, Pantaleo T, Bongianni F (2013) Neuronal mechanisms of respiratory pattern generation are evolutionary conserved. J Neurosci 33:9104-9112. CrossRef Medline

Cleveland WS (1979) Robust locally weighted regression and smoothing scatterplots. J Am Statist Assoc 74:829-836. CrossRef

Crapse TB, Sommer MA (2008) Corollary discharge across the animal kingdom. Nat Rev Neurosci 9:587-600. CrossRef Medline

DiCaprio RA, Billimoria CP, Ludwar BCh (2007) Information rate and spike-timing precision of proprioceptive afferents. J Neurophysiol 98: 1706-1717. CrossRef Medline

Fetcho JR, McLean DL (2010) Some principles of organization of spinal neurons underlying locomotion in zebrafish and their implications. Ann N Y Acad Sci 1198:94-104. CrossRef Medline

Ford JM, Mathalon DH (2005) Corollary discharge dysfunction in schizophrenia: can it explain auditory hallucinations? Int J Psychophysiol 58: 179-189. CrossRef Medline

Gariépy JF, Missaghi K, Chartré S, Robert M, Auclair F, Dubuc R (2012) Bilateral connectivity in the brainstem respiratory networks of lampreys. J Comp Neurol 520:1442-1456. CrossRef Medline

Goulding M (2009) Circuits controlling vertebrate locomotion: moving in a new direction. Nat Rev Neurosci 10:507-518. CrossRef Medline

Grillner S (2006) Biological pattern generation: the cellular and computational logic of networks in motion. Neuron 52:751-766. CrossRef Medline

Gutierrez GJ, O’Leary T, Marder E (2013) Multiple mechanisms switch an electrically coupled, synaptically inhibited neuron between competing rhythmic oscillators. Neuron 77:845-858. CrossRef Medline

Hägglund M, Dougherty KJ, Borgius L, Itohara S, Iwasato T, Kiehn O (2013) Optogenetic dissection reveals multiple rhythmogenic modules underlying locomotion. Proc Natl Acad Sci U S A 110:11589-11594. CrossRef Medline

Johnson SM, Koshiya N, Smith JC (2001) Isolation of the kernel for respiratory rhythm generation in a novel preparation: the pre-Botzinger complex “island". J Neurophysiol 85:1772-1776. Medline

Kiehn O (2006) Locomotor circuits in the mammalian spinal cord. Annu Rev Neurosci 29:279-306. CrossRef Medline

Kristan WB Jr, Calabrese RL, Friesen WO (2005) Neuronal control of leech behavior. Prog Neurobiol 76:279-327. CrossRef Medline

Lieske SP, Thoby-Brisson M, Telgkamp P, Ramirez JM (2000) Reconfiguration of the neural network controlling multiple breathing patterns: eupnea, sighs and gasps. Nat Neurosci 3:600-607. CrossRef Medline

Masino MA, Calabrese RL (2002) Phase relationships between segmentally organized oscillators in the leech heartbeat pattern generating network. J Neurophysiol 87:1572-1585. Medline

Moore JD, Deschenes M, Furuta T, Huber D, Smear MC, Demers M, Kleinfeld D (2013) Hierarchy of orofacial rhythms revealed through whisking and breathing. Nature 497:205-210. CrossRef Medline

Mullins OJ, Hackett JT, Buchanan JT, Friesen WO (2011) Neuronal control of swimming behavior: comparison of vertebrate and invertebrate model systems. Prog Neurobiol 93:244-269. CrossRef Medline

Mulloney B (1997) A test of the excitability-gradient hypothesis in the swimmeret system of crayfish. J Neurosci 17:1860-1868. Medline

Mulloney B (2003) During fictive locomotion, graded synaptic currents drive bursts of impulses in swimmeret motor neurons. J Neurosci 23: 5953-5962. Medline

Mulloney B (2005) A method to measure the strength of multi-unit bursts of action-potentials. J Neurosci Methods 146:98-105. CrossRef Medline

Mulloney B, Hall WM (2000) Functional organization of crayfish abdominal ganglia: III. Swimmeret motor neurons. J Comp Neurol 419:233-243. CrossRef Medline

Mulloney B, Hall WM (2003) Local commissural interneurons integrate information from intersegmental coordinating interneurons. J Comp Neurol 466:366-376. CrossRef Medline

Mulloney B, Hall WM (2007) Local and intersegmental interactions of coordinating neurons and local circuits in the swimmeret system. J Neurophysiol 98:405-413. CrossRef Medline

Mulloney B, Smarandache-Wellmann C (2012) Neurobiology of the crustacean swimmeret system. Prog Neurobiol 96:242-267. CrossRef Medline

Mulloney B, Tschuluun N, Hall WM (2003) Architectonics of crayfish ganglia. Microsc Res Tech 60:253-265. CrossRef Medline

Mulloney B, Harness PI, Hall WM (2006) Bursts of information: coordinating interneurons encode multiple parameters of a periodic motor pattern. J Neurophysiol 95:850-861. Medline

Namba H, Mulloney B (1999) Coordination of limb movements: three types of intersegmental interneurons in the swimmeret system and their responses to changes in excitation. J Neurophysiol 81:2437-2450. Medline

Perkel DH, Mulloney B (1974) Motor pattern production in reciprocally inhibitory neurons exhibiting postinhibitory rebound. Science 185:181183. CrossRef Medline

Poulet JF, Hedwig B (2003a) A corollary discharge mechanism modulates central auditory processing in singing crickets. J Neurophysiol 89:15281540. Medline 
Poulet JF, Hedwig B (2003b) Corollary discharge inhibition of ascending auditory neurons in the stridulating cricket. J Neurosci 23:4717-4725. Medline

Poulet JF, Hedwig B (2007) New insights into corollary discharges mediated by identified neural pathways. Trends Neurosci 30:14-21. CrossRef Medline

Puhl JG, Mesce KA (2010) Keeping it together: mechanisms of intersegmental coordination for a flexible locomotor behavior. J Neurosci 30:23732383. CrossRef Medline

Ryczko D, Charrier V, Ijspeert A, Cabelguen JM (2010) Segmental oscillators in axial motor circuits of the salamander: distribution and bursting mechanisms. J Neurophysiol 104:2677-2692. CrossRef Medline

Skinner FK, Mulloney B (1998) Intersegmental coordination of limb movements during locomotion: mathematical models predict circuits that drive swimmeret beating. J Neurosci 18:3831-3842. Medline

Skinner FK, Kopell N, Marder E (1994) Mechanisms for oscillation and frequency control in reciprocally inhibitory model neural networks. J Comput Neurosci 1:69-87. CrossRef Medline

Smarandache C, Hall WM, Mulloney B (2009) Coordination of rhythmic motor activity by gradients of synaptic strength in a neural circuit that couples modular neural oscillators. J Neurosci 29:9351-9360. CrossRef Medline

Smarandache-Wellmann C, Weller C, Wright TM Jr, Mulloney B (2013) Five types of nonspiking interneurons in local pattern-generating circuits of the crayfish swimmeret system. J Neurophysiol 110:344-357. CrossRef Medline

Smarandache-Wellmann C, Weller C, Mulloney B (2014) Mechanisms of coordination in distributed neural circuits: decoding and integration of coordinating information. J Neurosci 34:793-803. CrossRef Medline

Stein PS (2008) Motor pattern deletions and modular organization of turtle spinal cord. Brain Res Rev 57:118-124. CrossRef Medline

Tschuluun N, Hall WM, Mulloney B (2009) State-changes in the swimmeret system: a neural circuit that drives locomotion. J Exp Biol 212: 3605-3611. CrossRef Medline

von Holst E, Mittelstaedt H (1950) Das Reafferenzprinzip. Naturwissenschaften 37:464-476. CrossRef

von Uckermann G, Le Ray D, Combes D, Straka H, Simmers J (2013) Spinal efference copy signaling and gaze stabilization during locomotion in juvenile Xenopus frogs. J Neurosci 33:4253-4264. CrossRef Medline

Wang X-J, Rinzel J (1992) Alternating and synchronous rhythms in reciprocally inhibitory model neurons. Neural Comput 4:84-97. CrossRef

Wright TM Jr, Calabrese RL (2011) Patterns of presynaptic activity and synaptic strength interact to produce motor output. J Neurosci 31:1755517571. CrossRef Medline

Zhang C, Lewis TJ (2013) Phase response properties of half-center oscillators. J Comput Neurosci 35:55-74. CrossRef Medline

Zhang C, Guy RD, Mulloney B, Zhang Q, Lewis TJ (2014) The neural mechanism of optimal limb coordination in crustacean swimming. Proc Natl Acad Sci U S A, in press. 